\title{
In vivo application and dynamics of lactic acid bacteria for the four-season production of Vastedda-like cheese
}

\author{
Raimondo Gaglio a , Maria Luisa Scatassa b, Margherita Cruciata a , Viviana Miraglia b, Onofrio Corona ${ }^{\text {a }}$ \\ Rosalia Di Gerlando a , Baldassare Portolano ${ }^{a}$, Giancarlo Moschetti ${ }^{\text {a }}$, Luca Settanni ${ }^{\text {a,* }}$ \\ a Department of Agricultural and Forest Science, Università di Palermo, Viale delle Scienze 4, 90128 Palermo, Italy \\ b Istituto Zooprofilattico Sperimentale della Sicilia “Adelmo Mirri", Via G. Marinuzzi 3, 90129 Palermo, Italy
}

\section{A R T I C L E I N F O}

\section{Article history:}

Received 19 October 2013

Received in revised form 11 January 2014

Accepted 14 February 2014

Available online 20 February 2014

\section{Keywords:}

Fermentation

Lactic acid bacteria

Pilot plant

Raw milk

Starter cultures

Traditional cheese

\begin{abstract}
A B S T R A C T
Twelve lactic acid bacteria (LAB), previously selected in vitro (Gaglio et al., 2014), were evaluated in situ for their potential to act as starter cultures for the continuous four-season production of Vastedda-like cheese, made with raw ewes' milk. The strains belonged to Lactobacillus delbrueckii, Lactococcus lactis subsp. cremoris, Leuconostoc mesenteroides subsp. mesenteroides and Streptococcus thermophilus. LAB were first inoculated in multiple-strain combinations on the basis of their optimal growth temperatures in three process conditions which differed for milk treatment and medium for strain development: process 1 , growth of strains in the optimal synthetic media and pasteurised milk; process 2, growth of strains in whey based medium (WBM) and pasteurised milk; and process 3, growth of strains in WBM and raw milk. The strains that acidified the curds in short time, as shown by a pH drop, were all mesophilic and were then tested in a single inoculum through process 3 . Randomly amplified polymorphic DNA (RAPD)-PCR analysis applied to the colonies isolated from the highest dilutions of samples confirmed the dominance of the added strains after curd acidification, stretching and storage. After 15 days of refrigerated storage, the decrease in $\mathrm{pH}$ values showed an activity of the mesophilic strains at low temperatures, but only Lc. lactis subsp. cremoris PON153, Ln. mesenteroides subsp. mesenteroides PON259 and PON559 increased their number during the 15 days at $7{ }^{\circ} \mathrm{C}$. A sensory evaluation indicated that the cheeses obtained by applying protocol 3 and by inoculation with lactococci are the most similar to the protected denomination of origin (PDO) cheese and received the best scores by the judges. Thus, the experimental cheeses obtained with raw milk and inoculated with single and multiple combinations of lactococci were subjected to the analysis of the volatile organic compounds (VOCs) carried out by a headspace solid phase microextraction (SPME) technique coupled with gas chromatography with mass spectrometric detection (GC/MS). The dominance of lactococci over thermophilic LAB of raw milk was verified during summer production and, based on the combination of VOC profiles and sensory evaluation of the final cheeses, the multi-strain Lactococcus culture resulted in the most suitable starter preparation for the full-year production of Vastedda-like cheese.
\end{abstract}

(c) 2014 Elsevier B.V. All rights reserved.

\section{Introduction}

In the last years, the request for traditional dairy products increased and this phenomenon is still on the increase. Furthermore, the consumers demanding foods with no or reduced chemical preservatives for food conservation (Leite et al., 2006), determined a re-discovery of typical cheeses produced in restricted areas (Settanni et al., 2012a).

In Italy, the majority of ewes' milk cheeses are processed with raw milk and are considered to be traditional; some of them enjoy a

\footnotetext{
* Corresponding author. Tel.: + 39091 23896043; fax: + 390916515531

E-mail address: luca.settanni@unipa.it (L. Settanni).
}

"protected designation of origin" (PDO) status (Todaro et al., 2011). Within this group, "Vastedda della valle del Belìce" cheese is typical of the homonymous valley of Sicily (Italy); it is produced without the addition of starter cultures (GUE no. C 42/16 19.2.2010) applying the technology of stretched ("pasta filata") cheeses consisting of an acidification followed by the scalding of the acidified curd (Salvadori del Prato, 1998). "Vastedda della valle del Belìce" cheese does not undergo a ripening process, it is sealed under vacuum and kept under refrigeration until consumption which can take place after a short time from production (Mucchetti et al., 2008). This is in contrast with the general trend to use raw milk for extra-hard cheeses that are ripened for a long period (Settanni et al., 2013).

Raw milk cheeses deserve greater attention than cheeses made with thermally treated milk since the final products can become contaminated 
by pathogenic microorganisms as a result of their presence in raw milk, as well as their subsequent survival during the cheese making process (Donnelly, 2004). This is particularly true when the cheeses are consumed fresh, even though the stretching phase at high temperatures of pasta filata cheeses contributes to the safety of the resulting products.

Since cheeses can be obtained only if lactic acid bacteria (LAB) are present in milk before coagulation (Parente and Cogan, 2004), they should be contaminants of the milk or the equipment used for cheese making, or they must be added (Settanni and Moschetti, 2010). The last strategy may compromise the typicality of the final product, but the addition of autochthonous strains that derive from the environment/equipment and are highly adapted to the production area may provide the typical characteristics to cheeses (Micari et al., 2007).

An optimal starter culture for typical cheeses should drive the fermentation process in an appropriate direction by inhibiting the undesired microorganisms to warrant the hygienic aspects, but not alter the typical sensory profile of the traditional cheese (Settanni et al., 2013).

"Vastedda della valle del Belìce" cheese was traditionally produced only during the summer season, but it is currently requested throughout the year. This results in cheeses characterized by marked differences among the seasons, especially between summer and winter productions, and the final quality is unpredictable. Regarding the microbiology of cheeses, it might be greatly affected by the different temperatures registered in Sicily between summer, when the environmental temperatures may reach $30-35^{\circ} \mathrm{C}$, and winter with temperatures below $15^{\circ} \mathrm{C}$. Since the modern systematic approach to minimising microbial variability and obtaining cheeses with the desired characteristics, consistently over time, is based on the use of starter cultures, they should be constituted by autochthonous microorganisms which can ensure the maintenance of the typicality (Gaglio et al., 2014). At this respect, the strain selection for the four-season production of "Vastedda della valle del Belìce" cheese, has to consider the heat resistance during stretching and the capacity to carry out the acidification at high temperatures during summer as well as at low temperatures during winter.

With the aim to convert the production process for PDO "Vastedda della valle del Belìce" cheese from a production performed with raw milk without starters to a production carried out with raw milk and natural starters, during all four seasons of the year, the objectives of the present work were: to evaluate the in vivo acidifying ability of twelve strains of LAB; to evaluate their dynamics and to monitor their levels during the refrigerated storage of the experimental cheeses; and to select the strains providing the best cheeses in terms of sensory characteristics and volatile organic compounds.

\section{Materials and methods}

\subsection{Strains and growth conditions}

Twelve LAB strains (Lactobacillus delbrueckii PON79, PON256 and PON405, Lactococcus lactis PON36, PON153 and PON203, Leuconostoc mesenteroides PON169, PON259 and PON559, Streptococcus thermophilus PON244, PON120 and PON242), isolated from PDO Vastedda della Valle del Belìce cheese samples and selected as technologically relevant in cheese making based on their acidification activity, generation of aromatic compounds and production of antimicrobial substances (Gaglio et al., 2014), from a total of 74 strains, were used in this study. The strains belonging to the culture collection of the Agricultural Microbiology laboratory of the Department of Agricultural and Forestry Science - University of Palermo (Palermo, Italy), were grown overnight as follows: lactobacilli in MRS broth incubated at $42{ }^{\circ} \mathrm{C}$, streptococci in M17 broth incubated at $44{ }^{\circ} \mathrm{C}$, lactococci and leuconostocs in M17 broth at $30^{\circ} \mathrm{C}$. All media were purchased from Oxoid (Milan, Italy).

Lc. lactis strains were genetically identified at subspecies level applying the PCR amplification of the gene acmA as described by Garde et al.
(1999). The RAPD analysis tool reported by Pérez et al. (2002) was used to discriminate among the different subspecies of $L n$. mesenteroides.

\subsection{Cheese production}

The LAB strains were first mixed together in different multi-strain inocula: all strains belonging to each species in triple combination ( $\mathrm{Lb}$, lactobacilli; Lc, lactococci; Ln, leuconostocs; St, streptococci); all thermophilic strains (Lb-St, lactobacilli and streptococci); and all mesophilic strains (Lc-Ln, lactococci and leuconostocs). The bacterial mixtures were prepared after the individual overnight growth of each strain in different conditions: process 1 , after growth in the optimal synthetic medium, re-suspended in Ringer's solution [overnight cultures were centrifuged at $5000 \times g$ for 5 min, washed twice in Ringer's solution and re-suspended in the same solution till reaching an optical density (OD) at $600 \mathrm{~nm}$ of $c a .1 .00$ which approximately corresponds to a concentration of $10^{9} \mathrm{CFU} / \mathrm{mL}$ ) and inoculated in pasteurised $\left(72{ }^{\circ} \mathrm{C}\right.$ for $15 \mathrm{~s})$ ewes' milk; process 2, after growth in whey-based medium (WBM), prepared as reported by Settanni et al. (2012a), and inoculated in pasteurised ewes' milk; process 3 , after growth in WBM and inoculated in raw ewes' milk. The preparation of the cells for processes 2 and 3 was the same as that reported for process 1, but when OD600 was approximately 1.00 , the cells were centrifuged once again and resuspended in WBM in place of Ringer's solution. The inocula were added to a final concentration of approximately $10^{7} \mathrm{CFU} / \mathrm{mL}$ in milk. The multi-strain inocula included all strains at the same final concentration. Control cheeses were produced without the addition of starters: $\mathrm{CP} 1$, control for cheese making with pasteurised ewes' milk and Ringer's solution (process 1); $\mathrm{CP} 2$, control for cheese making with pasteurised ewes' milk and WBM (process 2); and CP3, control for cheese making with raw ewes' milk and WBM (process 3) (Fig. 1).

The experimental cheese making trials were carried out in a dairy pilot plant (Istituto Zooprofilattico Sperimentale della Sicilia "Adelmo Mirri”, Palermo, Italy) using the POLYFOOD mod. SI-050 (INVENTAGRI тм, Modena, Italy). Each trial was performed with $10 \mathrm{~L}$ of milk; according to the experimental plan, milk (heated at $38{ }^{\circ} \mathrm{C}$ ) was inoculated with the corresponding bacterial mixture and added with $3 \mathrm{~g}$ of rennet paste (Clerici Sacco International, Cadorago, Italy). After curdling, $1 \mathrm{~L}$ of $\mathrm{H}_{2} \mathrm{O}$ kept at $60{ }^{\circ} \mathrm{C}$ was added to each trial during the curd cutting until small rice-size grains were obtained. The curds were put into perforated containers and the $\mathrm{pH}$ was monitored electrometrically using the portable $\mathrm{pH}$ meter Russell RL060P (Thermo Fisher Scientific, Beverly, MA) at $1 \mathrm{~h}$ intervals for the first $6 \mathrm{~h}$ and, subsequently, at 12 $\mathrm{h}$ intervals until the value reached the range of 5.20-5.40. Room temperature of the experimental dairy factory where the acidification step took place was monitored by a 175-T2 data logger (Testo, Settimo Milanese, Italy). After acidification, the curds were stretched under hot $\left(85^{\circ} \mathrm{C}\right)$ water and moulded to a circular shape. The cheeses were salted in brine containing $20 \% \mathrm{NaCl}(\mathrm{w} / \mathrm{v})$ for $30 \mathrm{~min}$, air dried for $24 \mathrm{~h}$ and then kept refrigerated (at $7{ }^{\circ} \mathrm{C}$ ) under vacuum.

The strains whose combinations showed the best results in terms of kinetics of curd acidification were then tested individually (as reported above) in cheese making (Table 1 ) applying the conditions of process 3 , after growth in WBM and inoculated in raw ewes' milk.

Cheese trials were carried out in duplicate in two consecutive weeks during February 2013. pH measurements were carried out in duplicate for each trial at each time.

\subsection{Microbiological analyses}

The curds were collected soon after transfer into the perforated containers and, then, before stretching (acidified curds). The final cheeses were analysed soon after stretching and after 15 days of refrigerated storage. The first dilution of each sample ( $10 \mathrm{~g})$ was performed in sodium citrate $(2 \% \mathrm{w} / \mathrm{v})$ solution by homogenisation in a stomacher (BagMixer ${ }^{\circledR} 400$, Interscience, Saint Nom, France) for $2 \mathrm{~min}$ at the 
A

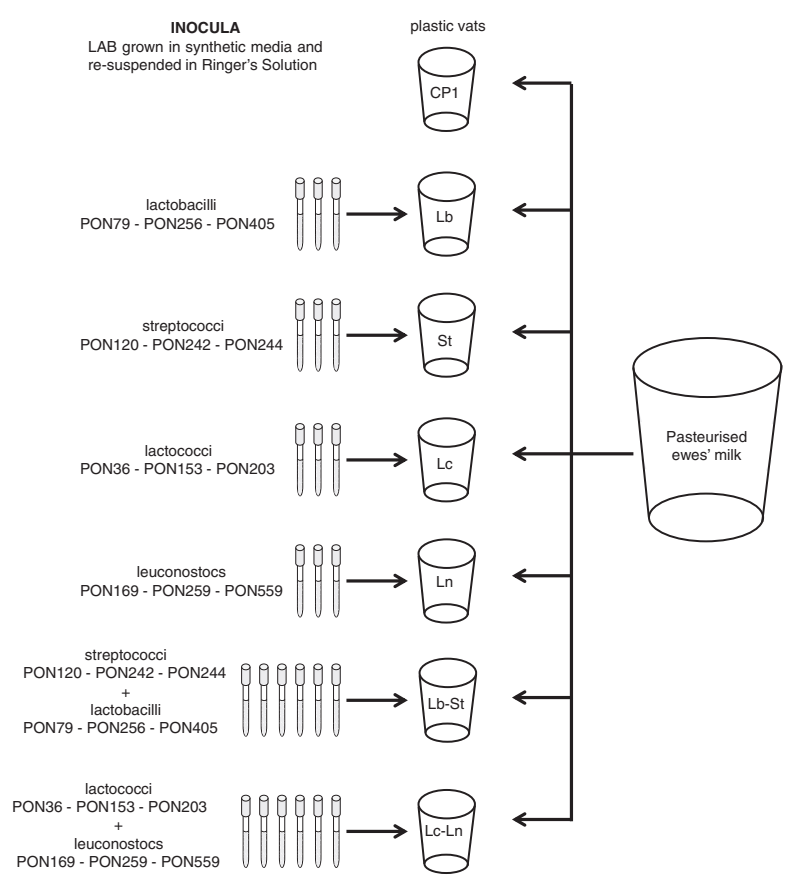

B

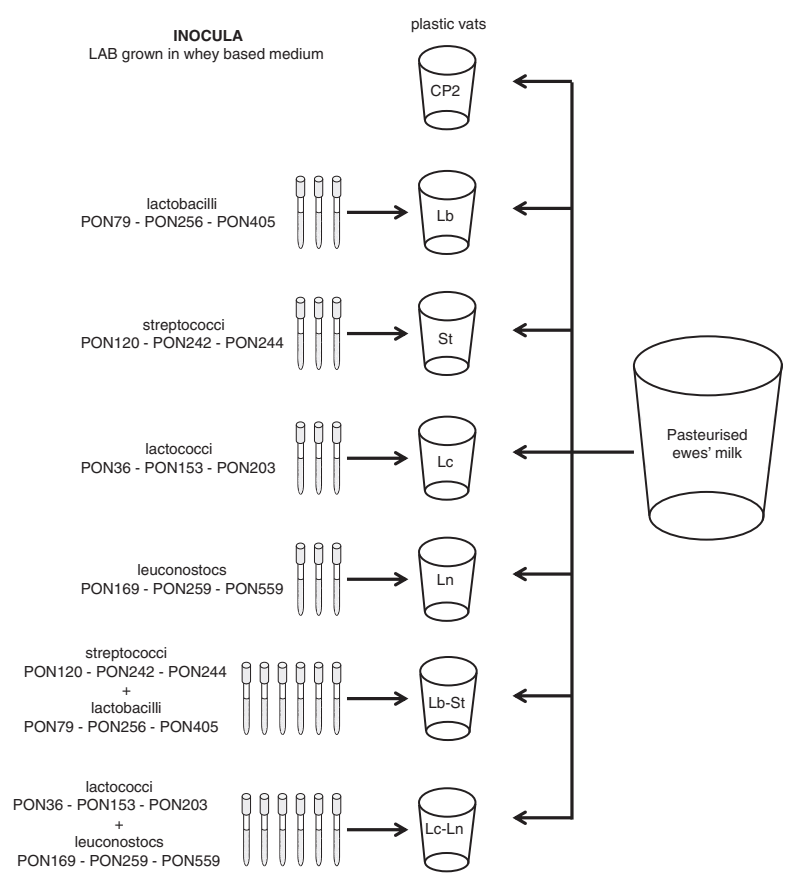

C

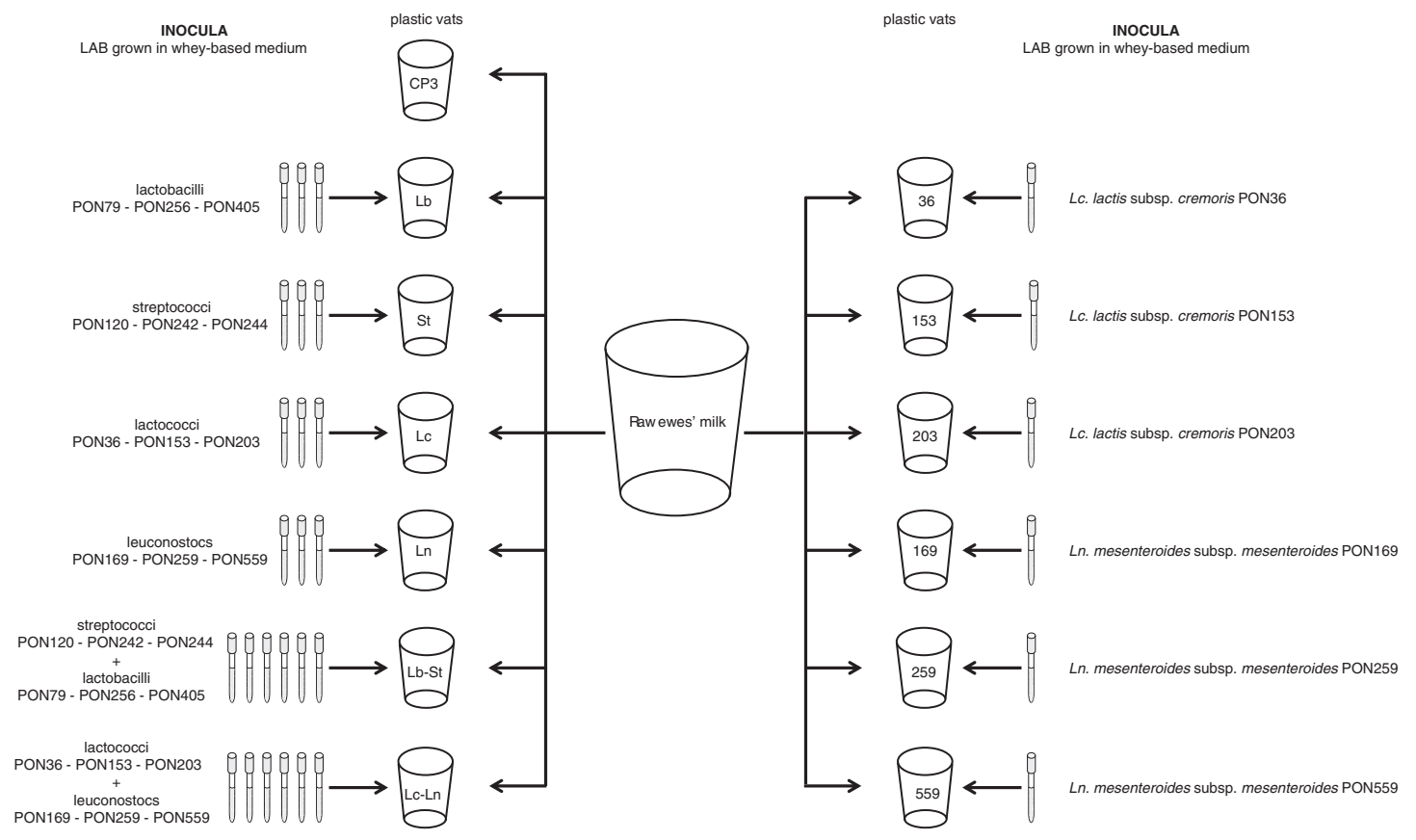

Fig. 1. Experimental design of Vastedda-like cheese productions performed at pilot plant scale. A, Process 1; B, process 2; C, process 3.

highest speed. Further serial dilutions were continued in Ringer's solution. Microbial suspensions were plated and incubated as follows: total mesophilic count (TMC) on plate count agar (PCA) with $1 \mathrm{~g} \mathrm{~L}^{-1}$ added skimmed milk (SkM), incubated aerobically at $30{ }^{\circ} \mathrm{C}$ for $72 \mathrm{~h}$; total psychrotrophic counts (TPC) on PCA-SkM, incubated aerobically at $7{ }^{\circ} \mathrm{C}$ for 7 days; mesophilic and thermophilic rod LAB on MRS agar, acidified at pH 5.4 with lactic acid $\left(5 \mathrm{~mol} \mathrm{~L}^{-1}\right)$, incubated anaerobically for $48 \mathrm{~h}$ at 30 and $44^{\circ} \mathrm{C}$, respectively; and mesophilic and thermophilic coccus LAB on M17 agar, incubated anaerobically for $48 \mathrm{~h}$ at 30 and
$44{ }^{\circ} \mathrm{C}$, respectively. TPC were monitored only during cheese storage. Microbiological counts were carried out in duplicate.

\subsection{Monitoring of the bacterial inocula}

The presence of the microorganisms added as starter cultures in the cheese trials with individual inocula (Lc. lactis PON36, PON153 and PON203 and Ln. mesenteroides PON169, PON259 and PON559) was confirmed, after colony isolation from the highest dilution of sample 
Table 1

Changes of pH during experimental Vastedda-like cheese making.

\begin{tabular}{|c|c|c|c|c|c|}
\hline Production process ${ }^{\mathrm{a}}$ & Inocula & $\mathrm{pH}$ curd at $\mathrm{T}_{0}$ & Time of curd $\mathrm{pH}$ in the range of 5.2-5.4 (value) & $\mathrm{pH}$ cheese at $\mathrm{T}_{0}$ & $\mathrm{pH}$ cheese at 15 days \\
\hline 1 & $\mathrm{CP} 1$ & $6.43 \pm 0.01$ & $120 \mathrm{~h}(5.20 \pm 0.02)$ & $5.57 \pm 0.02 \mathrm{~A}$ & $5.58 \pm 0.01 \mathrm{~A}$ \\
\hline 1 & $\mathrm{Lb}$ & $6.23 \pm 0.02$ & $72 \mathrm{~h}(5.36 \pm 0.01)$ & $5.48 \pm 0.01 \mathrm{~A}$ & $5.49 \pm 0.01 \mathrm{~A}$ \\
\hline 1 & St & $6.27 \pm 0.00$ & $120 \mathrm{~h}(5.39 \pm 0.01)$ & $5.40 \pm 0.00 \mathrm{~A}$ & $5.51 \pm 0.02 \mathrm{~A}$ \\
\hline 1 & Lc & $6.45 \pm 0.02$ & $5 \mathrm{~h}(5.23 \pm 0.03)$ & $5.54 \pm 0.02 \mathrm{~A}$ & $5.51 \pm 0.01 \mathrm{~A}$ \\
\hline 1 & Ln & $6.48 \pm 0.00$ & $5 \mathrm{~h}(5.24 \pm 0.01)$ & $5.52 \pm 0.01 \mathrm{~A}$ & $5.51 \pm 0.02 \mathrm{~A}$ \\
\hline 1 & Lb-St & $6.46 \pm 0.01$ & $72 \mathrm{~h}(5.39 \pm 0.01)$ & $5.49 \pm 0.01 \mathrm{~A}$ & $5.47 \pm 0.00 \mathrm{~A}$ \\
\hline 1 & Lc-Ln & $6.46 \pm 0.02$ & $5 \mathrm{~h}(5.19 \pm 0.01)$ & $5.60 \pm 0.02 \mathrm{~A}$ & $5.44 \pm 0.01 \mathrm{~B}$ \\
\hline 2 & $\mathrm{CP} 2$ & $6.42 \pm 0.01$ & $120 \mathrm{~h}(5.21 \pm 0.00)$ & $5.49 \pm 0.01 \mathrm{~A}$ & $5.47 \pm 0.01 \mathrm{~A}$ \\
\hline 2 & $\mathrm{Lb}$ & $6.08 \pm 0.01$ & 72 h $(5.40 \pm 0.00)$ & $5.49 \pm 0.00 \mathrm{~A}$ & $5.48 \pm 0.02 \mathrm{~A}$ \\
\hline 2 & St & $6.24 \pm 0.00$ & $120 \mathrm{~h}(5.31 \pm 0.00)$ & $5.50 \pm 0.01 \mathrm{~A}$ & $5.48 \pm 0.00 \mathrm{~A}$ \\
\hline 2 & Lc & $6.14 \pm 0.02$ & $3 \mathrm{~h}(5.26 \pm 0.01)$ & $5.50 \pm 0.00 \mathrm{~A}$ & $5.38 \pm 0.02 B$ \\
\hline 2 & Ln & $6.35 \pm 0.02$ & $5 \mathrm{~h}(5.32 \pm 0.02)$ & $5.38 \pm 0.01 \mathrm{~A}$ & $5.29 \pm 0.01 \mathrm{~B}$ \\
\hline 2 & Lb-St & $6.23 \pm 0.03$ & $48 \mathrm{~h}(5.26 \pm 0.00)$ & $5.51 \pm 0.01 \mathrm{~A}$ & $5.52 \pm 0.00 \mathrm{~A}$ \\
\hline 2 & Lc-Ln & $6.32 \pm 0.02$ & $5 \mathrm{~h}(5.21 \pm 0.02)$ & $5.53 \pm 0.00 \mathrm{~A}$ & $5.24 \pm 0.01 \mathrm{~B}$ \\
\hline 3 & $\mathrm{CP} 3$ & $6.48 \pm 0.00$ & $72 \mathrm{~h}(5.35 \pm 0.00)$ & $5.60 \pm 0.01 \mathrm{~A}$ & $5.57 \pm 0.01 \mathrm{~A}$ \\
\hline 3 & $\mathrm{Lb}$ & $6.55 \pm 0.01$ & $48 \mathrm{~h}(5.23 \pm 0.02)$ & $5.50 \pm 0.02 \mathrm{~A}$ & $5.49 \pm 0.00 \mathrm{~A}$ \\
\hline 3 & St & $6.42 \pm 0.02$ & $72 \mathrm{~h}(5.29 \pm 0.01)$ & $5.45 \pm 0.01 \mathrm{~A}$ & $5.43 \pm 0.02 \mathrm{~A}$ \\
\hline 3 & Lc & $6.11 \pm 0.00$ & $6 \mathrm{~h}(5.32 \pm 0.02)$ & $5.50 \pm 0.00 \mathrm{~A}$ & $5.10 \pm 0.01 \mathrm{~B}$ \\
\hline 3 & Ln & $6.35 \pm 0.01$ & $6 \mathrm{~h}(5.35 \pm 0.00)$ & $5.45 \pm 0.01 \mathrm{~A}$ & $5.19 \pm 0.00 \mathrm{~B}$ \\
\hline 3 & Lb-St & $6.39 \pm 0.02$ & $72 \mathrm{~h}(5.25 \pm 0.01)$ & $5.48 \pm 0.02 \mathrm{~A}$ & $5.44 \pm 0.01 \mathrm{~A}$ \\
\hline 3 & Lc-Ln & $6.37 \pm 0.00$ & $6 \mathrm{~h}(5.28 \pm 0.01)$ & $5.51 \pm 0.01 \mathrm{~A}$ & $5.17 \pm 0.00 \mathrm{~B}$ \\
\hline 3 & Lc. lactis subsp. cremoris PON36 & $6.66 \pm 0.01$ & $5 \mathrm{~h}(5.29 \pm 0.01)$ & $5.49 \pm 0.00 \mathrm{~A}$ & $5.29 \pm 0.02 B$ \\
\hline 3 & Lc. lactis subsp. cremoris PON153 & $6.67 \pm 0.00$ & $24 \mathrm{~h}(5.28 \pm 0.01)$ & $5.45 \pm 0.02 \mathrm{~A}$ & $5.30 \pm 0.00 \mathrm{~B}$ \\
\hline 3 & Lc. lactis subsp. cremoris PON203 & $6.65 \pm 0.02$ & $5 \mathrm{~h}(5.33 \pm 0.01)$ & $5.52 \pm 0.00 \mathrm{~A}$ & $5.32 \pm 0.01 \mathrm{~B}$ \\
\hline 3 & Ln. mesenteroides subsp. mesenteroides PON169 & $6.43 \pm 0.00$ & $6 \mathrm{~h}(5.37 \pm 0.00)$ & $5.48 \pm 0.01 \mathrm{~A}$ & $5.33 \pm 0.00 \mathrm{~B}$ \\
\hline 3 & Ln. mesenteroides subsp. mesenteroides PON259 & $6.47 \pm 0.02$ & $24 \mathrm{~h}(5.39 \pm 0.00)$ & $5.49 \pm 0.00 \mathrm{~A}$ & $5.28 \pm 0.02 B$ \\
\hline 3 & Ln. mesenteroides subsp. mesenteroides PON559 & $6.41 \pm 0.00$ & $24 \mathrm{~h}(5.33 \pm 0.02)$ & $5.54 \pm 0.02 \mathrm{~A}$ & $5.31 \pm 0.00 \mathrm{~B}$ \\
\hline
\end{tabular}

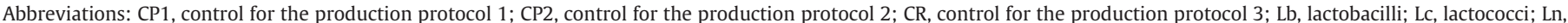
leuconostocs; St, streptococci; Lb-St, lactobacilli and streptococci; Lc-Ln, lactococci and leuconostocs.

Results indicate mean values \pm SD of four measurements (carried out in duplicate for two independent productions).

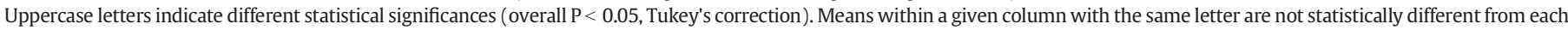
other.

a 1 , Growth of bacteria in the optimal synthetic media, re-suspension in Ringer's solution and inoculation in pasteurised ewes' milk; 2 , growth of bacteria in WBM and direct inoculation in pasteurised ewes' milk; 3 , growth of bacteria in WBM and direct inoculation in raw ewes' milk.

suspensions, by microscopic inspection and randomly amplified polymorphic DNA (RAPD) analysis. DNA from broth cultures was extracted by the Instagene Matrix kit (Bio-Rad, Hercules, CA) as described by the manufacturer. Crude cell extracts were used as template for PCR. RAPD-PCR was performed by means of T1 Thermocycler (Biometra, Göttingen, Germany) as reported by Settanni et al. (2012b). Amplified DNAs from the isolates of a given trial, together with that of the pure culture(s) corresponding to the same trial, were loaded onto a gel in order to recognise the inoculated bacteria.

\subsection{Sensory analysis}

The effect of the different bacterial inocula on the final characteristics of the cheeses was evaluated by sensory analysis on samples kept refrigerated for 15 days. A PDO Vastedda della Valle del Belìce cheese production conserved in the same conditions as the experimental cheeses was used for sensory comparison.

The descriptive panel consisted of thirteen judges (seven females and six males, 28-52 years old) familiar with the sensory analysis of cheeses, but not specifically trained in the evaluation of Vastedda della Valle del Belìce cheese. The judges were asked to score fourteen descriptors regarding the aspect (colour, oil, presence of eyes and uniformity of structure), the smell (strength of odours, pasture and pungent odour), the taste (taste intensity, salt, bitter and spicy) and the consistency (soft/hard, saliva evoking and dispersion).

The sensory analysis was conducted following the ISO 13299 (2003) indications. The panellists performed the analysis in individual chambers and had no specific information about the experimental design. All cheeses were administered in pieces of about $3 \times 3 \times 2 \mathrm{~cm}$ in size left at ambient temperature $\left(\mathrm{ca} .20^{\circ} \mathrm{C}\right.$ ) for $60 \mathrm{~min}$ and presented in coded white plastic plates in a randomised order.

\subsection{Analysis of cheese volatile organic compounds}

The cheeses which reached the best scores in terms of appearance, smell, taste and consistency were analysed for their volatile organic compound (VOC) composition after 15 days of refrigerated storage. VOCs were determined using the headspace solid phase microextraction (SPME) technique coupled with gas chromatography with mass spectrometric detection (GC/MS). The cheeses, frozen at $-20{ }^{\circ} \mathrm{C}$, were manually grated and $10 \mathrm{~g}$ of each cheese were transferred into a vial, added with $10 \mathrm{~mL} \mathrm{H}_{2} \mathrm{O}$ and $30 \mu \mathrm{L}$ of internal standard solution [4-methyl-2pentanone $(4.14 \mathrm{~g} / \mathrm{L})$ and isobutyric acid $(20 \mathrm{~g} / \mathrm{L})$ in $\mathrm{H}_{2} \mathrm{O}$ ]. The vials, kept under magnetic stirring, were heated at $60{ }^{\circ} \mathrm{C}$ until melting (Carlin and Versini, 2005) and the headspace was collected by DBV-carboxenPDMS fibres (Supelco, Bellefonte, PA) for $30 \mathrm{~min}$. The SPME fibre was inserted directly into a Finnegan Trace MS for GC/MS (Agilent 6890 Series GC system, Agilent 5973 Net Work Mass Selective Detector, Milan, Italy) equipped with a DB-WAX capillary column (Agilent Technologies, $30 \mathrm{~m}$, $0.250 \mathrm{~mm}$ i.d., film thickness $0.25 \mu \mathrm{m}$, part no. 122-7032). The GC temperature was $40^{\circ} \mathrm{C}$ for $2 \mathrm{~min}$ (during splitless injection), from 40 to $60{ }^{\circ} \mathrm{C}, 4{ }^{\circ} \mathrm{C} / \mathrm{min}, 60^{\circ} \mathrm{C}$ for $2 \mathrm{~min}$, from 60 to $190{ }^{\circ} \mathrm{C}, 2{ }^{\circ} \mathrm{C} / \mathrm{min}$, from 190 to $230{ }^{\circ} \mathrm{C}, 5{ }^{\circ} \mathrm{C} / \mathrm{min}, 230{ }^{\circ} \mathrm{C}$ for $15 \mathrm{~min}$; injector $250{ }^{\circ} \mathrm{C}$, Fid $250{ }^{\circ} \mathrm{C}$, transfer line $230^{\circ} \mathrm{C}$, carrier helium $1 \mathrm{~mL} / \mathrm{min}$; EM. $70 \mathrm{eV}$. Mass spectra were recorded by electronic impact (EI) at $70 \mathrm{eV}$ using ion source temperatures at $200{ }^{\circ} \mathrm{C}$. The scan mode was used to detect all the compounds in the range of $\mathrm{m} / \mathrm{z} 33-495$ atomic mass units (amu). The individual peaks were identified by comparison of their retention indices to those of authentic samples, as well as by comparing their mass spectra with the NIST/EPA/NIH Mass Spectral Library database (Version 2.0d, build 2005). The results were expressed in milligrams per kilogram as 4-methyl-2-pentanone. All solvents and reagents were purchased from WWR International (Milan, Italy). Chemical and physical determinations 
were performed in triplicate and the results expressed as means \pm standard deviation.

\subsection{Induction of the lytic cycle}

The search of the lysogenic state of the LAB showing the best results after sensory evaluation and VOC analysis was performed by the chemical induction of the lytic cycle, adapting the method of Cochran and Paul (1998). Overnight grown broth cultures were treated by adding mitomycin C (1 mg/mL). Controls were left untreated. After incubation for $24 \mathrm{~h}$ at room temperature in the dark, the presence of lytic phages was detected by the plaque assay modified (PAm) as described by Franciosi et al. (2009).

\subsection{Summer production of Vastedda-like cheese}

The strains showing the best performance during winter production were evaluated during summer to evaluate their ability to compete with the indigenous thermophilic LAB of raw milk. Summer production was carried out in duplicate between June and July 2013. In order to test the selected strains in "working" rather than "experimental" conditions, cheese making was performed at an industrial level in the dairy factory "Il Cacio Siciliano" located in Belmonte Mezzagno (Palermo, Italy), applying the same conditions as (process 3 ) the winter production. Acidification of curds, refrigerated storage of cheeses, strain recognition and VOC analysis were conducted as reported above.

\subsection{Statistical analyses}

Data of acidification and volatile organic compound concentration were statistically analysed using the ANOVA procedure. Differences between means were determined by Tukey's multiple-range test. Significance level was $\mathrm{P}<0.05$.

Sensory evaluations were analysed using the generalised linear model (GLM) procedure. The discrimination efficiency of the attributes for each assessor was tested by a 2-factor analysis of variance (ANOVA), with judges $(i=1 \ldots 11)$ and experimental cheeses $(j=1 . .27)$ as fixed factors. Least square means (LSM) were compared using $T$ test $(\mathrm{P}<0.05)$.

All statistical analyses were conducted using the software SAS 2004, version 9.1.2 (Statistical Analysis System Institute Inc., Cary, NC, USA).

\section{Results and discussion}

\subsection{Effect of bacterial inocula on the acidification kinetics of curds}

In this study, we evaluated the dynamics of mesophilic and thermophilic LAB strains during winter production of Vastedda-like cheese, assuming that mesophilic strains are able to perform curd acidification during summer whereas thermophilic strains may not be able to carry out this process during winter, when the temperatures are too low. The cheese making was conducted at pilot-scale level in standard conditions in order to keep all process variables, except temperature, under control and to avoid the casual effects of the factory-scale productions (Settanni et al., 2011). The entire experimentation was performed in February, which is one of the coldest months in Sicily. The temperature was not kept controlled during curd acidification to mimic the conditions of the artisanal cheese factories.

One of the medium used for LAB growth was prepared with whey, since LAB starters for the production of pasta-filata cheeses are commonly provided in the form of natural whey starter cultures (NWSC) (Parente et al., 1998). However, the strains tested in this study were isolated from cheese and, before the inocula could be provided in the form of whey starter cultures, their optimal development in whey had to be checked.

The acidification of curds determined by the addition of the selected LAB was followed until the value was comprised in the range of 5.20-
5.40 (Table 1) which corresponds to the level of acidity allowing the stretching of the curd (Niro, 2011). At those pH values most of dicalcium-para-caseinate gets converted into mono-calcium paracaseinate which provides the strings and sheen to the cheese (Kosikowski, 1958).

After genetic identification at subspecies level, all lactococci were found to belong to Lc. lactis subsp. cremoris, while all leuconostocs belonged to Ln. mesenteroides subsp. mesenteroides.

Room temperatures registered during the acidification step were in the range of $10.9-12.9{ }^{\circ} \mathrm{C}$ during the night ( 6 pm-6 am) and $13.8-$ $16.5^{\circ} \mathrm{C}$ during the day ( $\left.6 \mathrm{am}-6 \mathrm{pm}\right)$. Both curds of the control cheeses produced with pasteurised milk (CP1 and CP2) could be stretched after 5 days, while the curds of control cheese made with raw milk (CP3) reached a $\mathrm{pH}$ suitable for stretching at the third day of acidification. The triple inocula of lactobacilli acidified both pasteurised and raw milk before the triple inocula of streptococci. Generally lactobacilli and streptococci needed more time than leuconostocs and lactococci to acidify the curds. Lactobacilli determined a decrease in $\mathrm{pH}$ value in the range of 5.20-5.40 after $48 \mathrm{~h}$ in raw milk, while at least $72 \mathrm{~h}$ was necessary in pasteurised milk. Hence, the thermophilic combinations were not able to acidify in the time requested by the disciplinary of PDO "Vastedda della valle del Belìce" cheese (GUE no. C 42/16 19.2.2010).

Regarding mesophilic strains, lactococci were a stronger acidifier than leuconostocs and the best results were registered after the application of process 2, for which the pH reached 5.26 at $3 \mathrm{~h}$ from milk curdling. Although the application of process 3 reduced the time for the acidification by thermophilic strains, it delayed the drop of $\mathrm{pH}$ by lactococci and leuconostocs. This observation might be explained by the fact that the LAB, presumably mesophilic, present in raw milk overcame the thermophilic Lb, St and Lb-St inocula, but have undertaken a competition with Lc, Ln and Lc-Ln inocula. However, both mesophilic groups reached the wanted $\mathrm{pH}$ within $6 \mathrm{~h}$ from coagulation. The multiple strain/species combination showed results similar to those of the triple strain combinations of the single species, except Lc-Ln for process 2 which reached 5.21 after $5 \mathrm{~h}$, while Lc alone at $3 \mathrm{~h}$. Due to the rapid acidification of curds determined by the mesophilic strains in combination, all lactococci and leuconostocs were tested singly applying process 3 to register their behaviour in raw milk. Lc. lactis subsp. cremoris PON 153, Ln. mesenteroides subsp. mesenteroides PON259 and PON559 were not able to reach at least 5.40 within $6 \mathrm{~h}$, but Lc. lactis subsp. cremoris PON 36 and PON 203 determined a final pH of 5.29 and 5.33, respectively at the 5th hour from curdling. As a matter of fact, Lc. lactis subsp. cremoris PON153, and Ln. mesenteroides subsp. mesenteroides PON259 and PON559 showed an acidification kinetics compatible with the 24 $\mathrm{h}$ laid down by the PDO disciplinary, while the other mesophilic strains determined a too rapid process. However, a rapid acidification of the curd is important to prevent the growth of undesirable (spoilage/pathogenic) microorganisms.

Immediately after stretching, all Vastedda cheeses showed a $\mathrm{pH}$ value ranging between 5.38 and 5.60. The increase of $\mathrm{pH}$ after the stretching phase is a common phenomenon due to the loss of acids during treatment with hot water (Mucchetti and Neviani, 2006). After 15 days of refrigerated storage, the only $\mathrm{pH}$ that decreased consistently $(\mathrm{P}<0.05)$ were those determined by Lc, Ln and Lc-Ln inocula, showing a certain activity of the mesophilic combinations at low temperatures. The final $\mathrm{pH}$ registered in the presence of Lc. lactis subsp. cremoris and Ln. mesenteroides subsp. mesenteroides inoculated singly were higher than those displayed by the multiple combinations, but their values were significantly $(\mathrm{P}<0.05)$ different from those registered soon after production.

\subsection{Microbial dynamics}

Changes in the levels of concentration of TMC, mesophilic and thermophilic rod and coccus LAB during the acidification of curds and, 
Table 2

Microbial evolution during curd acidification.

\begin{tabular}{|c|c|c|c|c|c|c|c|c|c|}
\hline \multirow[t]{3}{*}{ Production protocol $^{\mathrm{a}}$} & \multirow[t]{3}{*}{ Inocula } & \multicolumn{8}{|l|}{ Sample } \\
\hline & & \multicolumn{4}{|l|}{ Curd at $\mathrm{T}_{0}$} & \multicolumn{4}{|c|}{ Curd before stretching } \\
\hline & & PCA-SkM $30{ }^{\circ} \mathrm{C}$ & $\begin{array}{l}\mathrm{M} 17 \\
30^{\circ} \mathrm{C}\end{array}$ & $\begin{array}{l}\text { MRS } \\
42{ }^{\circ} \mathrm{C}\end{array}$ & $\begin{array}{l}\mathrm{M} 17 \\
44^{\circ} \mathrm{C}\end{array}$ & PCA-SkM $30{ }^{\circ} \mathrm{C}$ & $\begin{array}{l}\mathrm{M} 17 \\
30{ }^{\circ} \mathrm{C}\end{array}$ & $\begin{array}{l}\text { MRS } \\
42{ }^{\circ} \mathrm{C}\end{array}$ & $\begin{array}{l}\text { M17 } \\
44^{\circ} \mathrm{C}\end{array}$ \\
\hline 1 & $\mathrm{CP} 1$ & $4.0 \pm 0.4$ & $3.7 \pm 0.5$ & $2.0 \pm 0.3$ & $2.5 \pm 0.1$ & $7.5 \pm 0.4$ & $7.5 \pm 0.5$ & $5.7 \pm 0.1$ & $5.7 \pm 0.4$ \\
\hline 1 & $\mathrm{Lb}$ & $7.0 \pm 0.2$ & n.d. & $7.9 \pm 0.2$ & n.d. & $7.9 \pm 0.5$ & n.d. & $7.6 \pm 0.5$ & n.d. \\
\hline 1 & St & $7.5 \pm 0.6$ & n.d. & n.d. & $7.4 \pm 0.4$ & $7.7 \pm 0.3$ & n.d. & n.d. & $7.8 \pm 0.2$ \\
\hline 1 & Lc & $8.0 \pm 0.4$ & $8.5 \pm 0.5$ & n.d. & n.d. & $8.7 \pm 0.2$ & $9.7 \pm 0.1$ & n.d. & n.d. \\
\hline 1 & Ln & $7.9 \pm 0.1$ & $8.6 \pm 0.3$ & n.d. & n.d. & $8.9 \pm 0.5$ & $9.9 \pm 0.2$ & n.d. & n.d. \\
\hline 1 & Lb-St & $7.3 \pm 0.5$ & n.d. & $7.5 \pm 0.4$ & $7.2 \pm 0.1$ & $7.4 \pm 0.4$ & n.d. & $7.8 \pm$ & $7.6 \pm 0.1$ \\
\hline 1 & Lc-Ln & $8.5 \pm 0.1$ & $9.1 \pm 0.3$ & n.d. & n.d. & $8.9 \pm 0.2$ & $10.1 \pm 0.1$ & n.d. & n.d. \\
\hline 2 & СР2 & $4.4 \pm 0.4$ & $4.1 \pm 0.3$ & $2.5 \pm 0.2$ & $2.5 \pm 0.3$ & $7.5 \pm 0.3$ & $7.4 \pm 0.2$ & $5.3 \pm 0.2$ & $6.0 \pm 0.3$ \\
\hline 2 & $\mathrm{Lb}$ & $6.9 \pm 0.6$ & n.d. & $7.7 \pm 0.3$ & n.d. & $7.6 \pm 0.3$ & n.d. & $7.4 \pm 0.1$ & n.d. \\
\hline 2 & St & $6.3 \pm 0.3$ & n.d. & n.d. & $7.7 \pm$ & $7.7 \pm 0.2$ & n.d. & n.d. & $7.3 \pm 0.6$ \\
\hline 2 & Lc & $8.6 \pm 0.3$ & $8.4 \pm 0.4$ & n.d. & n.d. & $9.8 \pm 0.4$ & $9.7 \pm 0.2$ & n.d. & n.d. \\
\hline 2 & Ln & $8.2 \pm 0.1$ & $8.1 \pm 0.2$ & n.d. & n.d. & $9.5 \pm 0.3$ & $9.7 \pm 0.4$ & n.d. & n.d. \\
\hline 2 & Lb-St & $6.9 \pm 0.4$ & n.d. & $7.2 \pm 0.4$ & $7.0 \pm 0.5$ & $7.5 \pm 0.2$ & n.d. & $7.7 \pm 0.4$ & $7.9 \pm 0.6$ \\
\hline 2 & Lc-Ln & $8.4 \pm 0.3$ & $8.7 \pm 0.2$ & n.d. & n.d. & $8.9 \pm 0.3$ & $10.0 \pm 0.1$ & n.d. & n.d. \\
\hline 3 & CP3 & $5.7 \pm 0.2$ & $6.0 \pm 0.4$ & $3.2 \pm 0.6$ & $4.9 \pm 0.5$ & $7.3 \pm 0.4$ & $7.6 \pm 0.1$ & $4.6 \pm 0.5$ & $5.3 \pm 0.4$ \\
\hline 3 & $\mathrm{Lb}$ & $7.1 \pm 0.3$ & n.d. & $7.6 \pm 0.2$ & n.d. & $7.5 \pm 0.1$ & n.d. & $7.9 \pm 0.1$ & n.d. \\
\hline 3 & St & $7.3 \pm 0.5$ & n.d. & n.d. & $7.3 \pm 0.6$ & $7.6 \pm 0.3$ & n.d. & n.d. & $7.9 \pm 0.1$ \\
\hline 3 & Lc & $7.5 \pm 0.6$ & $7.9 \pm 0.2$ & n.d. & n.d. & $9.0 \pm 0.4$ & $9.8 \pm 0.1$ & n.d. & n.d. \\
\hline 3 & Ln & $7.6 \pm 0.4$ & $8.1 \pm 0.1$ & n.d. & n.d. & $8.9 \pm 0.1$ & $9.5 \pm 0.1$ & n.d. & n.d. \\
\hline 3 & Lb-St & $7.7 \pm 0.1$ & n.d. & $7.7 \pm 0.2$ & $7.3 \pm 0.5$ & $7.6 \pm 0.4$ & n.d. & $7.5 \pm 0.4$ & $7.7 \pm 0.3$ \\
\hline 3 & Lc-Ln & $7.7 \pm 0.3$ & $8.3 \pm 0.1$ & n.d. & n.d. & $9.1 \pm 0.1$ & $9.7 \pm 0.4$ & n.d. & n.d. \\
\hline 3 & Lc. lactis subsp. cremoris PON36 & $7.5 \pm 0.6$ & $8.1 \pm 0.4$ & n.d. & n.d. & $9.0 \pm 0.1$ & $9.5 \pm 0.2$ & n.d. & n.d. \\
\hline 3 & Lc. lactis subsp. cremoris PON153 & $7.8 \pm 0.4$ & $7.9 \pm 0.2$ & n.d. & n.d. & $8.7 \pm 0.3$ & $9.4 \pm 0.5$ & n.d. & n.d. \\
\hline 3 & Lc. lactis subsp. cremoris PON203 & $7.3 \pm 0.6$ & $7.9 \pm 0.1$ & n.d. & n.d. & $8.6 \pm 0.5$ & $9.3 \pm 0.4$ & n.d. & n.d. \\
\hline 3 & Ln. mesenteroides subsp. mesenteroides PON169 & $7.5 \pm 0.1$ & $7.8 \pm 0.3$ & n.d. & n.d. & $8.5 \pm 0.2$ & $9.5 \pm 0.2$ & n.d. & n.d. \\
\hline 3 & Ln. mesenteroides subsp. mesenteroides PON259 & $7.6 \pm 0.4$ & $7.5 \pm 0.1$ & n.d. & n.d. & $7.8 \pm 0.6$ & $8.2 \pm 0.1$ & n.d. & n.d. \\
\hline 3 & Ln. mesenteroides subsp. mesenteroides PON559 & $7.5 \pm 0.2$ & $7.2 \pm 0.4$ & n.d. & n.d. & $8.6 \pm 0.4$ & $9.0 \pm 0.3$ & n.d. & n.d. \\
\hline
\end{tabular}

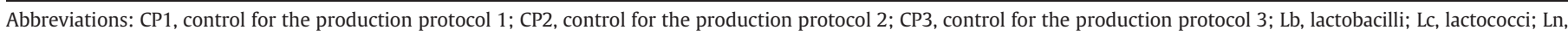
leuconostocs; St, streptococci; Lb-St, lactobacilli and streptococci; Lc-Ln, lactococci and leuconostocs.

Results indicate mean values \pm SD of four plate counts (carried out in duplicate for two independent productions).

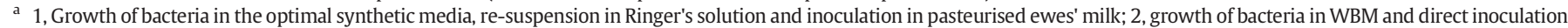
in pasteurised ewes' milk; 3, growth of bacteria in WBM and direct inoculation in raw ewes' milk.

subsequently, the refrigerated storage are shown in Tables 2 and 3. In Table 3, the evolution of TPC is also reported.

All the three curds obtained from the control cheese productions (CP1, CP2 and CP3) were characterized by the highest counts on M17 agar, indicating the dominance of mesophilic coccus LAB, which concentrations were comparable with those of TMC (Table 2). All curds obtained from the milks inoculated with the thermophilic LAB, rods or cocci, mono-species or multi-species combinations, did not show increases in their numbers during the acidification of any of the process considered. On the contrary, all curds started with mesophilic LAB showed an increase of concentrations of this group of at least 1 Log; the highest levels were registered for the combination Lc-Ln of the processes 1 and 2 which reached 10.1 and $10.0 \mathrm{Log} C F \mathrm{~g}$, respectively, in $5 \mathrm{~h}$. The single inoculum of Lc. lactis subsp. cremoris and Ln. mesenteroides subsp. mesenteroides were all characterized by the increase of the mesophilic LAB concentration, but Ln. mesenteroides subsp. mesenteroides PON259 increased this level until barely 8.2 Log CFU/g, whereas all other five strains determined a final level above $9.00 \mathrm{Log} \mathrm{CFU} / \mathrm{g}$.

After stretching (Table 3), the levels of TPC ranged between 4.7 and $8.0 \mathrm{Log}$ CFU/g. The lowest concentration of TPC was displayed by CP2, while the highest by Lc-Ln of process 2 . The levels of TMC of the cheeses were due to the LAB inoculated. At the 15th day of refrigerated storage, only the cheeses started with mesophilic LAB showed the final levels of this group at high concentrations. Also control cheeses were characterized by high levels of mesophilic LAB which were almost 2.00 Log cycles higher than thermophilic LAB. The cheeses obtained with a single inoculum of mesophilic LAB were not all characterized by high numbers of mesophilic LAB after 15 days of storage, except for Lc. lactis subsp. cremoris PON153 and Ln. mesenteroides subsp. mesenteroides PON259, which reached the levels of 9.0 and $8.5 \mathrm{Log} \mathrm{CFU} / \mathrm{g}$, respectively, showing a consistent increase of their concentrations; the other 4 mesophilic strains did not seem to have increased during refrigeration.

Although the growth at sub-optimal temperatures results in a dramatic slow down of metabolism of Lc. lactis, strains of this species can develop at $4{ }^{\circ} \mathrm{C}$ (Panoff et al., 1994). The slowed metabolism of the mesophilic strains may play a relevant role to impact the sensory profile of cheeses that are kept refrigerated after production and are not subjected to ripening.

\subsection{Strain recognition}

The isolates collected from the highest dilutions of samples, were analysed at the strain level by means of RAPD-PCR with primer M13 in order to monitor the dynamics of the added strains. The direct comparison of the RAPD patterns (Fig. 2) allowed the recognition of the cultures in all 24 trials inoculated with selected LAB alone or in combination. This approach allowed the assessment of the evolution of the added LAB. In the multi-strain combinations, it allowed the establishment of the dominance of Lc. lactis subsp. cremoris PON153 and Ln. mesenteroides subsp. mesenteroides PON259 over the other mesophilic strains and revealed that the thermophilic combinations were not able to develop at dominant levels during the acidification step, but found them still viable after 15 days at $7{ }^{\circ} \mathrm{C}$ (results not shown). The RAPD profiles of the $\mathrm{LAB}$ isolated at the highest concentrations from the control curds and cheeses excluded the presence of any of the 12 LAB used as starter in raw and pasteurised milk (results not shown). RAPD analysis is currently applied to monitor starter cultures at strain level during food production. 
Table 3

Microbial evolution during refrigerated Vastedda-like cheese storage.

\begin{tabular}{|c|c|c|c|c|c|c|c|c|c|c|c|}
\hline \multirow[t]{3}{*}{ Production protocol ${ }^{\mathrm{a}}$} & \multirow[t]{3}{*}{ Inocula } & \multicolumn{10}{|l|}{ Sample } \\
\hline & & \multicolumn{5}{|l|}{ Cheese at $\mathrm{T}_{0}$} & \multicolumn{5}{|c|}{ Cheese at 15 days } \\
\hline & & PCA-SkM $7{ }^{\circ} \mathrm{C}$ & $\begin{array}{l}\text { PCA-SkM } \\
30^{\circ} \mathrm{C}\end{array}$ & $\begin{array}{l}\mathrm{M} 17 \\
30{ }^{\circ} \mathrm{C}\end{array}$ & $\begin{array}{l}\text { MRS } \\
42{ }^{\circ} \mathrm{C} \\
\end{array}$ & $\begin{array}{l}\text { M17 } \\
44{ }^{\circ} \mathrm{C}\end{array}$ & PCA $77^{\circ} \mathrm{C}$ & $\begin{array}{l}\text { PCA } \\
30^{\circ} \mathrm{C}\end{array}$ & $\begin{array}{l}\text { M17 } \\
30{ }^{\circ} \mathrm{C}\end{array}$ & $\begin{array}{l}\text { MRS } \\
42{ }^{\circ} \mathrm{C}\end{array}$ & $\begin{array}{l}\text { M17 } \\
44^{\circ} \mathrm{C}\end{array}$ \\
\hline 1 & $\mathrm{CP} 1$ & $6.0 \pm 0.1$ & $7.9 \pm 0.5$ & $7.9 \pm 0.1$ & $7.0 \pm 0.3$ & $7.3 \pm 0.2$ & $7.9 \pm 0.5$ & $7.6 \pm 0.1$ & $8.5 \pm 0.5$ & $5.0 \pm 0.2$ & $7.4 \pm 0.1$ \\
\hline 1 & $\mathrm{Lb}$ & $6.2 \pm 0.3$ & $7.6 \pm 0.2$ & n.d. & $6.9 \pm 0.3$ & n.d. & $8.7 \pm 0.3$ & $8.0 \pm 0.2$ & & $7.0 \pm 0.3$ & \\
\hline 1 & St & $6.7 \pm 0.1$ & $7.3 \pm 0.2$ & n.d. & n.d. & $7.5 \pm 0.5$ & $7.9 \pm 0.4$ & $8.0 \pm 0.4$ & n.d. & n.d. & $6.2 \pm 0.3$ \\
\hline 1 & Lc & $6.7 \pm 0.5$ & $8.6 \pm 0.4$ & $8.6 \pm 0.1$ & n.d. & n.d. & $7.5 \pm 0.1$ & $8.7 \pm 0.2$ & $8.6 \pm 0.4$ & n.d. & n.d. \\
\hline 1 & Ln & $7.1 \pm 0.4$ & $8.6 \pm 0.2$ & $8.5 \pm 0.5$ & n.d. & n.d. & $7.2 \pm 0.3$ & $8.7 \pm 0.5$ & $8.7 \pm 0.3$ & n.d. & n.d. \\
\hline 1 & Lb-St & $6.0 \pm 0.2$ & $7.0 \pm 0.2$ & n.d. & $7.6 \pm 0.4$ & $7.7 \pm 0.3$ & $6.5 \pm 0.1$ & $9.0 \pm 0.1$ & n.d. & $6.5 \pm 0.5$ & $7.0 \pm 0.1$ \\
\hline 1 & Lc-Ln & $7.4 \pm 0.5$ & $7.9 \pm 0.1$ & $8.1 \pm 0.5$ & n.d. & n.d. & $8.0 \pm 0.3$ & $9.0 \pm 0.2$ & $9.4 \pm 0.1$ & n.d. & n.d. \\
\hline 2 & $\mathrm{CP} 2$ & $4.7 \pm 0.3$ & $8.9 \pm 0.3$ & $8.9 \pm 0.3$ & $6.2 \pm 0.3$ & $6.3 \pm 0.5$ & $8.0 \pm 0.4$ & $8.3 \pm 0.3$ & $9.0 \pm 0.5$ & $5.7 \pm 0.1$ & $6.5 \pm 0.4$ \\
\hline 2 & $\mathrm{Lb}$ & $6.7 \pm 0.1$ & $6.5 \pm 0.4$ & n.d. & $6.7 \pm 0.3$ & n.d. & $7.0 \pm 0.1$ & $7.7 \pm 0.2$ & n.d. & $7.8 \pm 0.3$ & n.d. \\
\hline 2 & St & $6.4 \pm 0.2$ & $6.5 \pm 0.1$ & n.d. & n.d. & $6.6 \pm 0.5$ & $6.7 \pm 0.3$ & $7.0 \pm 0.1$ & n.d. & n.d. & $6.7 \pm 0.2$ \\
\hline 2 & Lc & $7.0 \pm 0.1$ & $9.1 \pm 0.5$ & $8.8 \pm 0.1$ & n.d. & n.d. & $7.7 \pm 0.1$ & $9.4 \pm 0.3$ & $9.4 \pm 0.4$ & n.d. & n.d. \\
\hline 2 & Ln & $7.0 \pm 0.4$ & $9.1 \pm 0.1$ & $8.9 \pm 0.3$ & n.d. & n.d. & $7.8 \pm 0.4$ & $9.0 \pm 0.2$ & $9.0 \pm 0.5$ & n.d. & n.d. \\
\hline 2 & Lb-St & $6.7 \pm 0.2$ & $7.1 \pm 0.1$ & n.d. & $6.9 \pm 0.3$ & $6.7 \pm 0.1$ & $7.8 \pm 0.2$ & $7.9 \pm 0.3$ & n.d. & $7.0 \pm 0.4$ & $6.9 \pm 0.3$ \\
\hline 2 & Lc-Ln & $8.0 \pm 0.3$ & $10.0 \pm 0.4$ & $8.9 \pm 0.1$ & n.d. & n.d. & $8.3 \pm 0.3$ & $8.4 \pm 0.5$ & $8.3 \pm 0.2$ & n.d. & n.d. \\
\hline 3 & $\mathrm{CP} 3$ & $6.4 \pm 0.1$ & $8.0 \pm 0.3$ & $7.7 \pm 0.2$ & $4.7 \pm 0.3$ & $6.9 \pm 0.2$ & $7.5 \pm 0.1$ & $7.8 \pm 0.4$ & $7.9 \pm 0.4$ & $7.0 \pm 0.1$ & $7.5 \pm 0.3$ \\
\hline 3 & $\mathrm{Lb}$ & $6.1 \pm 0.4$ & $7.3 \pm 0.3$ & n.d. & $7.1 \pm 0.4$ & n.d. & $7.7 \pm 0.5$ & $8.2 \pm 0.4$ & n.d. & $7.2 \pm 0.1$ & n.d. \\
\hline 3 & St & $6.2 \pm 0.5$ & $7.7 \pm 0.4$ & n.d. & n.d. & $7.5 \pm 0.1$ & $7.2 \pm 0.3$ & $8.5 \pm 0.3$ & n.d. & n.d. & $6.3 \pm 0.4$ \\
\hline 3 & Lc & $5.7 \pm 0.3$ & $8.3 \pm 0.2$ & $8.4 \pm 0.3$ & n.d. & n.d. & $7.8 \pm 0.2$ & $8.5 \pm 0.1$ & $9.0 \pm 0.2$ & n.d. & n.d. \\
\hline 3 & Ln & $6.3 \pm 0.2$ & $8.1 \pm 0.1$ & $8.2 \pm 0.2$ & n.d. & n.d. & $7.5 \pm 0.3$ & $8.5 \pm 0.2$ & $8.7 \pm 0.2$ & n.d. & n.d. \\
\hline 3 & Lb-St & $6.6 \pm 0.4$ & $7.4 \pm 0.5$ & n.d. & $7.1 \pm 0.3$ & $7.2 \pm 0.4$ & $7.0 \pm 0.1$ & $8.2 \pm 0.4$ & n.d. & $6.4 \pm 0.3$ & $6.7 \pm 0.1$ \\
\hline 3 & Lc-Ln & $6.9 \pm 0.5$ & $8.1 \pm 0.2$ & $8.0 \pm 0.3$ & n.d. & n.d. & $7.9 \pm 0.4$ & $8.3 \pm 0.3$ & $8.6 \pm 0.5$ & n.d. & n.d. \\
\hline 3 & Lc. lactis subsp. cremoris PON36 & $6.0 \pm 0.1$ & $6.2 \pm 0.2$ & $6.0 \pm 0.1$ & n.d. & n.d. & $6.5 \pm 0.4$ & $6.0 \pm 0.1$ & $5.7 \pm 0.3$ & n.d. & n.d. \\
\hline 3 & Lc. lactis subsp. cremoris PON153 & $6.0 \pm 0.2$ & $8.2 \pm 0.4$ & $8.0 \pm 0.2$ & n.d. & n.d. & $8.6 \pm 0.2$ & $8.4 \pm 0.2$ & $9.0 \pm 0.1$ & n.d. & n.d. \\
\hline 3 & Lc. lactis subsp. cremoris PON203 & $5.9 \pm 0.2$ & $8.4 \pm 0.1$ & $7.5 \pm 0.2$ & n.d. & n.d. & $7.4 \pm 0.3$ & $7.8 \pm 0.4$ & $7.6 \pm 0.2$ & n.d. & n.d. \\
\hline 3 & Ln. mesenteroides subsp. mesenteroides PON169 & $6.0 \pm 0.4$ & $6.3 \pm 0.1$ & $5.7 \pm 0.4$ & n.d. & n.d. & $7.2 \pm 0.4$ & $7.2 \pm 0.3$ & $6.8 \pm 0.2$ & n.d. & n.d. \\
\hline 3 & Ln. mesenteroides subsp. mesenteroides PON259 & $7.7 \pm 0.2$ & $7.1 \pm 0.5$ & $8.1 \pm 0.1$ & n.d. & n.d. & $8.6 \pm 0.3$ & $8.4 \pm 0.1$ & $8.5 \pm 0.4$ & n.d. & n.d. \\
\hline 3 & Ln. mesenteroides subsp. mesenteroides PON559 & $6.5 \pm 0.1$ & $8.6 \pm 0.4$ & $8.3 \pm 0.3$ & n.d. & n.d. & $8.2 \pm 0.4$ & $8.5 \pm 0.3$ & $8.6 \pm 0.1$ & n.d. & n.d. \\
\hline
\end{tabular}

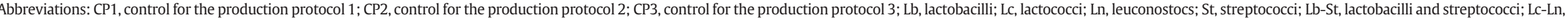
actococci and leuconostocs.

Results indicate mean values \pm SD of four plate counts (carried out in duplicate for two independent productions).

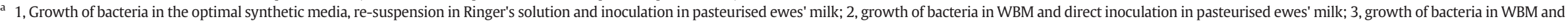
direct inoculation in raw ewes' milk. 
A
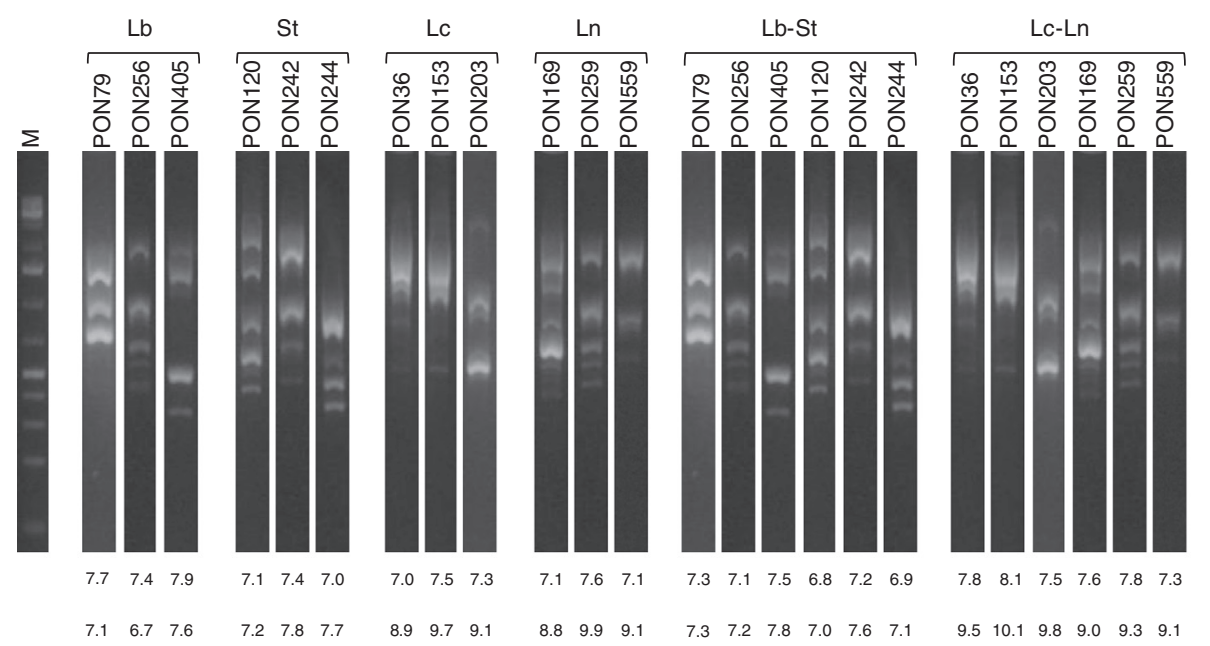

Curd $\mathrm{T}_{0}$

$\begin{array}{lll}7.0 & 7.5 & 7.3\end{array}$

$\begin{array}{lll}7.1 & 7.6 & 7.1\end{array}$

$\begin{array}{llllll}7.3 & 7.1 & 7.5 & 6.8 & 7.2 & 6.9\end{array}$

$\begin{array}{llllll}7.8 & 8.1 & 7.5 & 7.6 & 7.8 & 7.3\end{array}$

Acidified curd

$\begin{array}{lll}8.9 & 9.7 & 9.1\end{array}$

$\begin{array}{lll}8.8 & 9.9 & 9.1\end{array}$

$\begin{array}{llllll}7.3 & 7.2 & 7.8 & 7.0 & 7.6 & 7.1\end{array}$

$\begin{array}{llllll}9.5 & 10.1 & 9.8 & 9.0 & 9.3 & 9.1\end{array}$

B
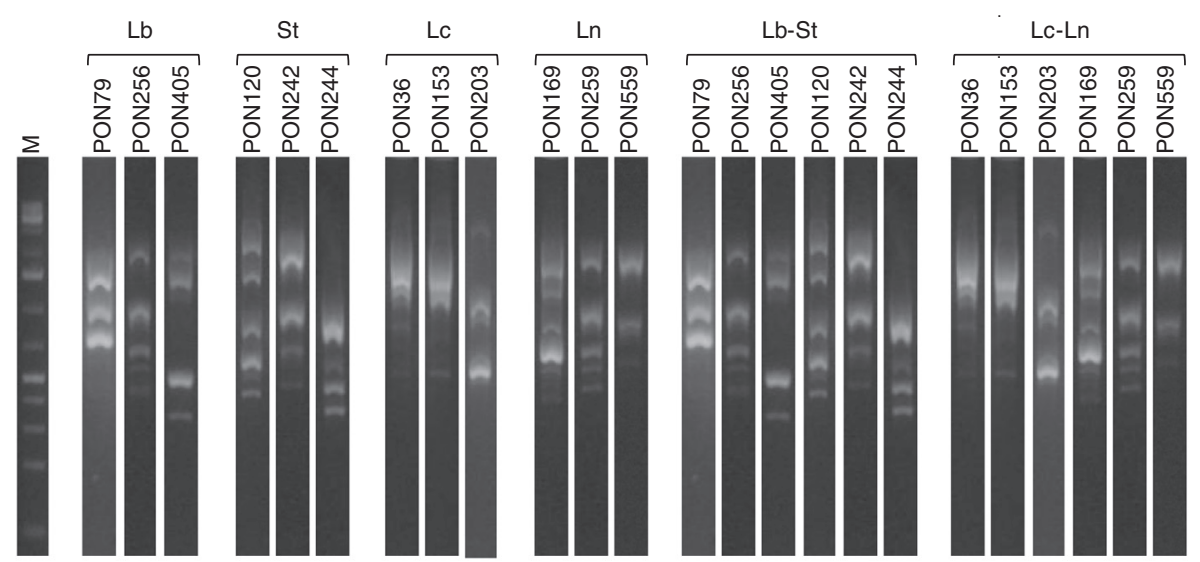

Curd $\mathrm{T}_{0}$

$\begin{array}{lll}7.3 & 7.5 & 7.7\end{array}$
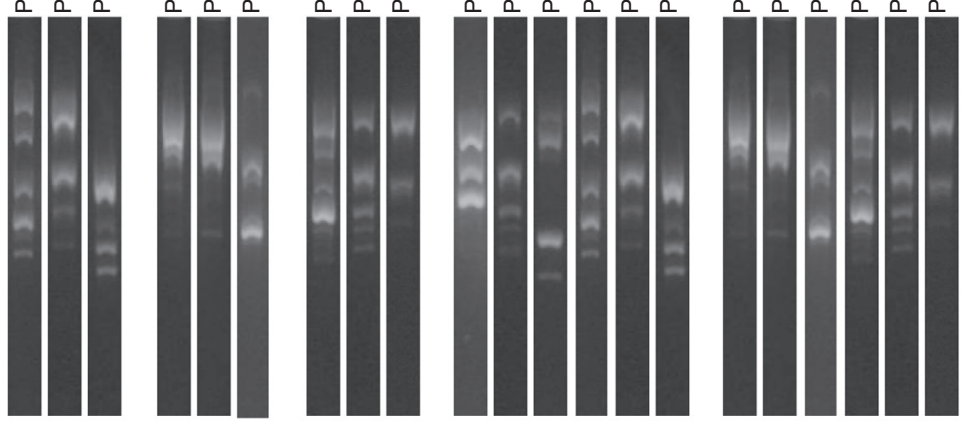

$\begin{array}{llllll}6.8 & 6.8 & 7.2 & 6.8 & 7.0 & 6.7\end{array}$

$\begin{array}{llllll}7.1 & 7.7 & 7.2 & 7.0 & 6.9 & 6.9\end{array}$

Acidified curd

$\begin{array}{lll}7.3 & 7.1 & 7.4\end{array}$

$\begin{array}{lll}7.1 & 7.3 & 7.4\end{array}$

$\begin{array}{lll}8.5 & 9.7 & 8.9\end{array}$

$\begin{array}{lll}8.5 & 9.7 & 8.9\end{array}$

$\begin{array}{llllll}7.1 & 7.2 & 7.7 & 7.1 & 7.9 & 6.9\end{array}$

$\begin{array}{llllll}8.9 & 10.0 & 9.1 & 8.5 & 7.8 & 8.1\end{array}$

\section{C}
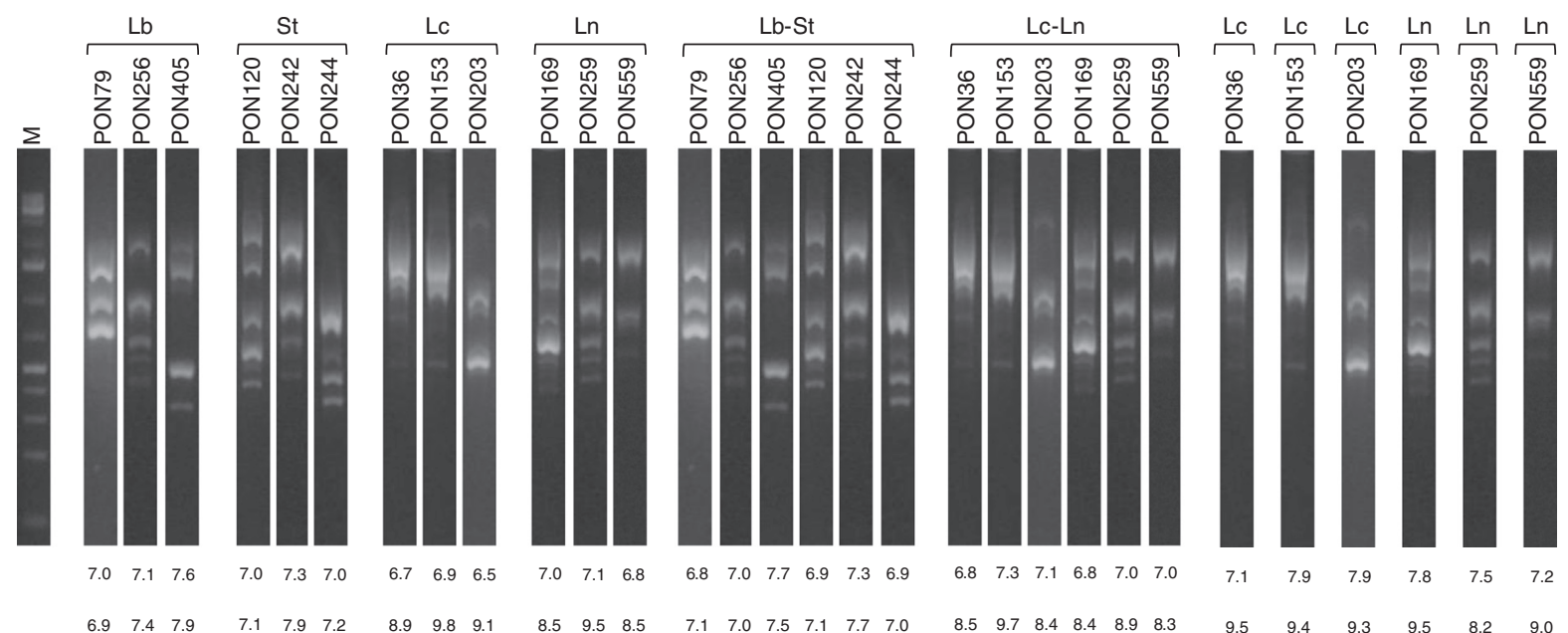

Acidified curd

$\begin{array}{llllll}6.9 & 7.4 & 7.9 & 7.1 & 7.9 & 7.2\end{array}$

$\begin{array}{lll}6.7 & 6.9 & 6.5 \\ & & \end{array}$

$\begin{array}{lll}7.0 & 7.1 & 6.8\end{array}$

$\begin{array}{lllllll}6.8 & 7.0 & 7.7 & 6.9 & 7.3 & 6.9\end{array}$

$\begin{array}{llllll}6.8 & 7.3 & 7.1 & 6.8 & 7.0 & 7.0\end{array}$

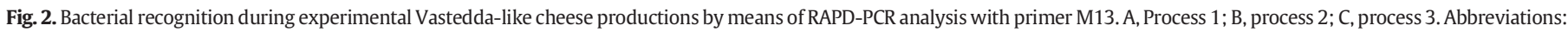

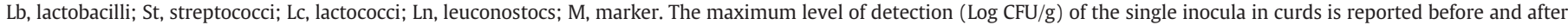
acidification.

\subsection{Sensory evaluation}

The results of the sensory evaluation carried out by the judges on the 27 experimental cheeses and a PDO Vastedda della Valle del Belìce cheese, in duplicate, are reported in Table 4 . The addition of cheeses processed with the traditional PDO protocol is fundamental for the evaluation of the final characteristics imparted by the different strains (Settanni et al., 2013). Except for the uniformity of the structure, 
Table 4

Sensory characteristics of experimental Vastedda-like cheeses.

\begin{tabular}{|c|c|c|c|c|c|c|c|c|c|c|c|c|c|c|c|}
\hline \multirow[t]{2}{*}{ Production protocol ${ }^{\mathrm{a}}$} & \multirow[t]{2}{*}{ Cheese samples } & \multicolumn{14}{|c|}{ Attributes } \\
\hline & & Colour & Oil & Eyes & Uniformity & Strength of odours & Pasture & Pungent odour & Taste intensity & Salt & Bitter & Spicy & Soft/hard & Saliva evoking & Dispersion \\
\hline PDO & Market cheese & 3.46 & 1.08 & 1.62 & 1.46 & 2.31 & 1.15 & 1.23 & 1.77 & 1.69 & 1.31 & 1.15 & 3.92 & 1.31 & 3.08 \\
\hline 1 & $\mathrm{CP} 1$ & 3.62 & 2.54 & 3.00 & 3.77 & 2.08 & 1.00 & 1.92 & 2.69 & 1.92 & 3.77 & 1.31 & 3.46 & 1.85 & 2.85 \\
\hline 1 & Lb & 4.23 & 1.54 & 2.69 & 3.77 & 2.23 & 1.00 & 1.62 & 2.00 & 1.85 & 3.00 & 1.00 & 3.38 & 1.23 & 2.77 \\
\hline 1 & St & 3.92 & 1.77 & 2.08 & 1.92 & 1.54 & 1.00 & 2.08 & 3.08 & 2.54 & 2.54 & 1.00 & 4.00 & 2.08 & 2.77 \\
\hline 1 & Lc & 3.15 & 1.00 & 1.31 & 1.31 & 1.46 & 1.15 & 1.46 & 1.46 & 1.62 & 1.62 & 1.00 & 3.77 & 1.77 & 2.38 \\
\hline 1 & Ln & 3.15 & 1.00 & 1.80 & 1.80 & 1.69 & 1.00 & 1.54 & 2.15 & 1.15 & 2.00 & 1.15 & 3.85 & 1.85 & 3.00 \\
\hline 1 & Lb-St & 4.23 & 1.46 & 2.23 & 2.85 & 2.15 & 1.00 & 1.62 & 1.92 & 2.00 & 1.85 & 1.00 & 3.00 & 1.38 & 2.15 \\
\hline 1 & Lc-Ln & 3.15 & 1.08 & 1.92 & 1.90 & 1.46 & 1.00 & 1.15 & 1.92 & 1.23 & 2.15 & 1.00 & 3.85 & 1.62 & 3.00 \\
\hline 2 & $\mathrm{CP} 2$ & 4.08 & 1.38 & 2.08 & 2.85 & 2.23 & 1.00 & 1.38 & 2.08 & 1.62 & 1.92 & 1.77 & 3.15 & 1.85 & 2.77 \\
\hline 2 & $\mathrm{Lb}$ & 3.77 & 1.77 & 2.08 & 4.69 & 1.92 & 1.00 & 1.92 & 2.77 & 1.62 & 4.00 & 1.00 & 4.08 & 1.54 & 2.92 \\
\hline 2 & St & 3.46 & 1.54 & 1.46 & 1.92 & 1.85 & 1.00 & 1.69 & 3.00 & 2.85 & 2.08 & 1.38 & 3.92 & 2.15 & 2.85 \\
\hline 2 & LC & 4.54 & 1.08 & 1.31 & 1.62 & 2.23 & 1.62 & 1.69 & 2.31 & 1.46 & 2.62 & 1.08 & 3.00 & 1.92 & 2.77 \\
\hline 2 & Ln & 4.54 & 1.00 & 1.77 & 1.92 & 1.92 & 1.15 & 1.38 & 1.92 & 1.46 & 1.46 & 1.00 & 2.85 & 1.46 & 2.38 \\
\hline 2 & Lb-St & 4.38 & 1.23 & 1.77 & 1.92 & 1.46 & 1.15 & 2.38 & 2.77 & 1.77 & 1.92 & 1.15 & 3.08 & 2.00 & 2.85 \\
\hline 2 & Lc-Ln & 3.15 & 1.00 & 2.54 & 2.54 & 1.69 & 1.00 & 1.62 & 2.08 & 1.23 & 1.85 & 1.08 & 4.00 & 1.62 & 3.00 \\
\hline 3 & CP3 & 3.47 & 1.00 & 1.62 & 1.62 & 2.62 & 1.08 & 1.85 & 1.31 & 1.62 & 1.54 & 1.08 & 4.15 & 1.85 & 3.00 \\
\hline 3 & $\mathrm{Lb}$ & 3.77 & 1.15 & 2.54 & 3.77 & 1.92 & 1.00 & 1.15 & 1.38 & 1.62 & 1.62 & 1.15 & 3.00 & 1.38 & 3.00 \\
\hline 3 & St & 3.77 & 1.00 & 1.92 & 1.92 & 2.00 & 1.00 & 1.38 & 1.38 & 1.38 & 1.08 & 1.08 & 4.15 & 1.08 & 3.00 \\
\hline 3 & Lc & 3.31 & 1.38 & 1.31 & 1.31 & 2.15 & 1.00 & 1.00 & 1.62 & 2.00 & 1.54 & 1.15 & 3.15 & 1.54 & 3.62 \\
\hline 3 & Ln & 3.77 & 1.23 & 1.86 & 1.31 & 1.92 & 1.00 & 1.08 & 1.77 & 1.38 & 1.85 & 1.62 & 3.38 & 1.46 & 2.85 \\
\hline 3 & Lb-St & 3.31 & 1.00 & 1.00 & 1.00 & 2.15 & 1.00 & 1.77 & 1.62 & 1.23 & 1.31 & 1.15 & 3.92 & 1.77 & 3.15 \\
\hline 3 & Lc-Ln & 3.31 & 1.00 & 3.62 & 2.08 & 2.08 & 1.08 & 1.62 & 2.23 & 1.08 & 1.77 & 1.00 & 3.77 & 1.38 & 3.00 \\
\hline 3 & Lc. lactis subsp. cremoris PON36 & 3.77 & 1.08 & 1.62 & 1.92 & 2.00 & 1.08 & 1.00 & 1.62 & 1.15 & 1.46 & 1.23 & 3.77 & 1.00 & 3.08 \\
\hline 3 & Lc. lactis subsp. cremoris PON153 & 3.77 & 1.00 & 1.92 & 1.92 & 2.31 & 1.00 & 1.23 & 1.54 & 1.69 & 1.00 & 1.23 & 3.31 & 1.46 & 2.54 \\
\hline 3 & Lc. lactis subsp. cremoris PON203 & 4.08 & 1.00 & 1.31 & 1.31 & 2.23 & 1.00 & 1.15 & 1.46 & 1.38 & 1.46 & 1.15 & 3.23 & 1.31 & 2.85 \\
\hline 3 & Ln. mesenteroides subsp. mesenteroides PON169 & 3.46 & 1.00 & 1.81 & 2.54 & 1.77 & 1.15 & 1.00 & 1.08 & 1.00 & 1.46 & 1.00 & 3.54 & 1.23 & 2.85 \\
\hline 3 & Ln. mesenteroides subsp. mesenteroides PON259 & 3.92 & 1.00 & 1.92 & 1.92 & 2.15 & 1.08 & 1.46 & 1.00 & 1.38 & 1.15 & 1.08 & 3.54 & 1.00 & 2.85 \\
\hline 3 & Ln. mesenteroides subsp. mesenteroides PON559 & 3.92 & 1.00 & 1.91 & 1.62 & 2.46 & 1.08 & 1.23 & 1.08 & 1.08 & 1.38 & 1.00 & 3.92 & 1.15 & 2.62 \\
\hline SEM & & 0.23 & 0.16 & 0.38 & 0.43 & 0.24 & 0.08 & 0.25 & 0.28 & 0.22 & 0.28 & 0.14 & 0.22 & 0.18 & 0.16 \\
\hline \multicolumn{16}{|l|}{ Statistical significance: } \\
\hline Judges & & $* * *$ & $* * *$ & ** & NS & $* * *$ & * & * & *** & $* * *$ & *** & $* * *$ & $* * *$ & $* * *$ & ** \\
\hline Cheeses & & $* * *$ & $* * *$ & $* * *$ & $* * *$ & $*$ & $* * *$ & ** & $* * *$ & $* * *$ & $* * *$ & $* *$ & $* * *$ & $* * *$ & $* * *$ \\
\hline
\end{tabular}

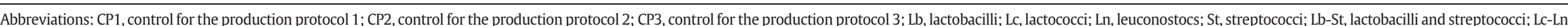
lactococci and leuconostocs; LSM, least square means; SEM, standard error of means; NS = not significant.

Results indicate mean values.

Values reported in bold were identical for PDO cheese and experimental cheeses processed with mono-culture inocula.

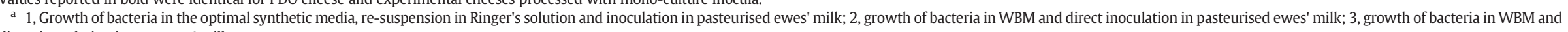
direct inoculation in raw ewes' milk.

${ }_{* *}^{*} \mathrm{P} \leq 0.05$

** $\mathrm{P} \leq 0.01$. 
Table 5

Analysis of volatile organic compounds emitted from 15-day refrigerated experimental Vastedda-like cheeses.

\begin{tabular}{|c|c|c|c|c|c|c|c|c|c|c|c|c|}
\hline \multirow[t]{3}{*}{ Chemical compounds $^{\mathrm{a}}$} & \multicolumn{12}{|l|}{ Cheeses } \\
\hline & \multicolumn{6}{|c|}{ Winter production } & \multicolumn{6}{|c|}{ Summer production } \\
\hline & PDO & $\mathrm{CP} 3$ & PON36 & PON153 & PON203 & Lc & PDO & $\mathrm{CP} 3$ & PON36 & PON153 & PON203 & LC \\
\hline Isoamyl alcohol & $0.50 \pm 0.05 \mathrm{~A}$ & $0.14 \pm 0.02 B$ & $0.71 \pm 0.04 \mathrm{~B}$ & $0.55 \pm 0.04 \mathrm{~A}$ & $1.51 \pm 0.07 \mathrm{~B}$ & $1.89 \pm 0.07 \mathrm{~B}$ & $0.54 \pm 0.08 \mathrm{~A}$ & $1.05 \pm 0.11 \mathrm{~B}$ & $1.43 \pm 0.19 \mathrm{~B}$ & $0.97 \pm 0.09 \mathrm{~B}$ & $1.17 \pm 0.10 \mathrm{~B}$ & $1.26 \pm 0.21 \mathrm{~B}$ \\
\hline Ethyl esanoate & $0.47 \pm 0.08 \mathrm{~A}$ & n.d. & n.d. & $0.67 \pm 0.04 \mathrm{~A}$ & n.d. & n.d. & $0.52 \pm 0.08 \mathrm{~A}$ & & & $0.29 \pm 0.03 \mathrm{~B}$ & & \\
\hline 1-Pentanol & $0.05 \pm 0.02 \mathrm{~A}$ & $0.04 \pm 0.01 \mathrm{~A}$ & $0.08 \pm 0.02 \mathrm{~A}$ & $0.03 \pm 0.01 \mathrm{~A}$ & $0.07 \pm 0.01 \mathrm{~A}$ & $0.06 \pm 0.01 \mathrm{~A}$ & $0.08 \pm 0.01 \mathrm{~A}$ & n.d. & n.d. & n.d. & n.d. & n.d. \\
\hline Acetoin & $0.45 \pm 0.02 \mathrm{~A}$ & $0.14 \pm 0.02 \mathrm{~B}$ & $0.31 \pm 0.02 \mathrm{~B}$ & $0.36 \pm 0.02 \mathrm{~B}$ & $0.60 \pm 0.04 \mathrm{~B}$ & $0.05 \pm 0.01 \mathrm{~B}$ & $0.14 \pm 0.02 \mathrm{~A}$ & n.d. & n.d. & $0.06 \pm 0.01 \mathrm{~B}$ & n.d. & n.d. \\
\hline 1-Hexanol & $0.02 \pm 0.01 \mathrm{~A}$ & n.d. & $0.06 \pm 0.01 \mathrm{~B}$ & n.d. & $0.02 \pm 0.01 \mathrm{~A}$ & $0.05 \pm 0.01 \mathrm{~A}$ & $0.09 \pm 0.01 \mathrm{~A}$ & n.d. & n.d. & $0.01 \pm 0 \mathrm{~B}$ & n.d. & n.d. \\
\hline 2-Nonanone & n.d. & n.d. & n.d. & n.d. & n.d. & n.d. & $0.21 \pm 0.02 \mathrm{~A}$ & $0.02 \pm 0 \mathrm{~B}$ & n.d. & $0.12 \pm 0.01 \mathrm{~B}$ & $0.01 \pm 0.01 \mathrm{~B}$ & $0.03 \pm 0.01 \mathrm{~B}$ \\
\hline Ethyl octanoate & $0.39 \pm 0.04 \mathrm{~A}$ & n.d. & n.d. & $0.51 \pm 0.04 \mathrm{~B}$ & n.d. & n.d. & $0.46 \pm 0.08 \mathrm{~A}$ & n.d. & n.d. & $0.06 \pm 0.01 \mathrm{~B}$ & n.d. & n.d. \\
\hline Acetic acid & $4.44 \pm 0.11 \mathrm{~A}$ & $0.65 \pm 0.04 \mathrm{~B}$ & $0.49 \pm 0.04 \mathrm{~B}$ & $4.26 \pm 0.09 \mathrm{~A}$ & $0.09 \pm 0.02 \mathrm{~B}$ & $1.90 \pm 0.07 \mathrm{~B}$ & $1.38 \pm 0.13 \mathrm{~A}$ & $0.17 \pm 0.02 \mathrm{~B}$ & $0.16 \pm 0.01 \mathrm{~B}$ & $0.73 \pm 0.05 \mathrm{~B}$ & $0.17 \pm 0.02 \mathrm{~B}$ & $0.33 \pm 0.03 B$ \\
\hline Benzaldehyde & $0.07 \pm 0.02 \mathrm{~A}$ & n.d. & $0.10 \pm 0.02 \mathrm{~A}$ & $0.03 \pm 0.01 \mathrm{~B}$ & $0.05 \pm 0.01 \mathrm{~A}$ & $0.06 \pm 0.01 \mathrm{~B}$ & $0.06 \pm 0.01 \mathrm{~A}$ & $0.01 \pm 0 \mathrm{~B}$ & $0.02 \pm 0 \mathrm{~B}$ & $0.01 \pm 0 \mathrm{~B}$ & $0.01 \pm 0 \mathrm{~B}$ & $0.02 \pm 0.01 \mathrm{~B}$ \\
\hline 2,3-Butanediol isomer & $4.47 \pm 0.05 \mathrm{~A}$ & $1.07 \pm 0.05 \mathrm{~B}$ & n.d. & $5.44 \pm 0.11 \mathrm{~B}$ & $0.01 \pm 0.01 \mathrm{~B}$ & $3.79 \pm 0.10 \mathrm{~B}$ & $0.07 \pm 0.02 \mathrm{~A}$ & $0.08 \pm 0.02 \mathrm{~A}$ & $0.11 \pm 0.02 \mathrm{~A}$ & $0.07 \pm 0.03 \mathrm{~A}$ & $0.08 \pm 0.01 \mathrm{~A}$ & $0.14 \pm 0.03 \mathrm{~B}$ \\
\hline Phenylacetaldehyde & $0.07 \pm 0.02 \mathrm{~A}$ & n.d. & $0.06 \pm 0.01 \mathrm{~A}$ & n.d. & $0.05 \pm 0.01 \mathrm{~A}$ & n.d. & n.d. & n.d. & n.d. & $0.01 \pm 0$ & n.d. & n.d. \\
\hline Butyric acid & $4.51 \pm 0.11 \mathrm{~A}$ & $0.58 \pm 0.04 \mathrm{~B}$ & $1.49 \pm 0.07 \mathrm{~B}$ & $5.21 \pm 0.11 \mathrm{~B}$ & $0.30 \pm 0.04 \mathrm{~B}$ & $1.32 \pm 0.07 \mathrm{~B}$ & $4.40 \pm 0.21 \mathrm{~A}$ & $0.29 \pm 0.06 \mathrm{~B}$ & $0.59 \pm 0.03 \mathrm{~B}$ & $2.35 \pm 0.04 \mathrm{~B}$ & $0.31 \pm 0.10 \mathrm{~B}$ & $2.25 \pm 0.02 \mathrm{~B}$ \\
\hline Ethyl decanoate & $0.60 \pm 0.04 \mathrm{~A}$ & n.d. & n.d. & $0.57 \pm 0.04 \mathrm{~A}$ & $0.01 \pm 0.01 \mathrm{~B}$ & $0.05 \pm 0.01 \mathrm{~B}$ & $0.54 \pm 0.04 \mathrm{~A}$ & n.d. & n.d. & n.d. & n.d. & $0.01 \pm 0 \mathrm{~B}$ \\
\hline Hexanoic acid & $17.57 \pm 0.28 \mathrm{~A}$ & $1.95 \pm 0.07 \mathrm{~B}$ & $5.75 \pm 0.11 \mathrm{~B}$ & $19.67 \pm 0.19 \mathrm{~B}$ & $1.12 \pm 0.06 \mathrm{~B}$ & $3.41 \pm 0.09 \mathrm{~B}$ & $22.59 \pm 0.15 \mathrm{~A}$ & $1.87 \pm 0.10 \mathrm{~B}$ & $4.66 \pm 0.09 \mathrm{~B}$ & $11.75 \pm 0.04 \mathrm{~B}$ & $1.67 \pm 0.13 \mathrm{~B}$ & $11.00 \pm 0.07 \mathrm{~B}$ \\
\hline 2-Phenylethanol & $0.14 \pm 0.03 \mathrm{~A}$ & $0.02 \pm 0.01 \mathrm{~B}$ & $0.05 \pm 0.01 \mathrm{~B}$ & $0.10 \pm 0.01 \mathrm{~A}$ & $0.16 \pm 0.02 \mathrm{~A}$ & $0.28 \pm 0.02 \mathrm{~B}$ & $0.07 \pm 0.01 \mathrm{~A}$ & $0.09 \pm 0.02 \mathrm{~A}$ & $0.07 \pm 0.01 \mathrm{~A}$ & $0.05 \pm 0.01 \mathrm{~A}$ & $0.11 \pm 0.02 \mathrm{~A}$ & $0.11 \pm 0.01 \mathrm{~A}$ \\
\hline Heptanoic acid & $0.27 \pm 0.03 \mathrm{~A}$ & n.d. & n.d. & $0.31 \pm 0.02 \mathrm{~A}$ & n.d. & n.d. & $0.26 \pm 0.03 \mathrm{~A}$ & n.d. & n.d. & n.d. & n.d. & n.d. \\
\hline Octanoic acid & $15.18 \pm 0.31 \mathrm{~A}$ & $0.53 \pm 0.04 \mathrm{~B}$ & $1.78 \pm 0.07 \mathrm{~B}$ & $23.19 \pm 0.21 \mathrm{~B}$ & $0.29 \pm 0.02 \mathrm{~B}$ & $0.84 \pm 0.07 \mathrm{~B}$ & $10.44 \pm 0.98 \mathrm{~A}$ & $0.40 \pm 0.12 B$ & $0.15 \pm 0.01 \mathrm{~B}$ & $5.17 \pm 0.06 \mathrm{~B}$ & $0.17 \pm 0.02 \mathrm{~B}$ & $0.32 \pm 0.08 \mathrm{~B}$ \\
\hline Nonanoic acid & $0.12 \pm 0.02 \mathrm{~A}$ & $0.03 \pm 0.01 \mathrm{~B}$ & $0.06 \pm 0.01 \mathrm{~B}$ & $0.22 \pm 0.02 \mathrm{~B}$ & $0.01 \pm 0.01 \mathrm{~B}$ & $0.05 \pm 0.01 \mathrm{~B}$ & $0.09 \pm 0.01 \mathrm{~A}$ & $0.02 \pm 0 \mathrm{~B}$ & $0.01 \pm 0 \mathrm{~B}$ & $0.01 \pm 0 \mathrm{~B}$ & $0.01 \pm 0 \mathrm{~B}$ & $0.02 \pm 0.01 \mathrm{~B}$ \\
\hline Decanoic acid & $7.58 \pm 0.18 \mathrm{~A}$ & $0.07 \pm 0.01 \mathrm{~B}$ & $0.42 \pm 0.04 \mathrm{~B}$ & $9.38 \pm 0.12 \mathrm{~B}$ & $0.08 \pm 0.01 \mathrm{~B}$ & $0.11 \pm 0.02 \mathrm{~B}$ & $2.75 \pm 0.01 \mathrm{~A}$ & $0.16 \pm 0.04 \mathrm{~B}$ & $0.11 \pm 0.02 \mathrm{~B}$ & $1.13 \pm 0.03 \mathrm{~B}$ & $0.02 \pm 0 \mathrm{~B}$ & $0.03 \pm 0.01 \mathrm{~B}$ \\
\hline
\end{tabular}

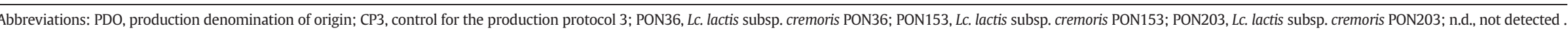
Results indicate mean values of three measurements and are expressed (in $\mathrm{mg} / \mathrm{kg}$ ) as 4-methyl-2-pentanone.

Uppercase letters indicate different statistical significances (overall $\mathrm{P}<0.05$, Tukey's correction). Means between columns of a given season with the same letter are not statistically different.

The chemicals are shown following their retention time. 
which was not significantly different among judges, all other sensory attributes were different both for judges and cheeses. The less notable differences were evidenced by pasture and pungent odour among judges and strength of odours among cheeses. Control experimental cheeses, except CP3 regarding the presence of eyes, showed scores different from that of the PDO cheese for all other attributes. On the contrary, PDO cheese showed the same scores as the cheeses obtained applying protocol 3 with lactococci for oil, eyes, strength of odours, spicy, pungent odour, salt, saliva evoking and dispersion and the same scores as the cheeses obtained with the same process inoculated with leuconostocs for colour, pasture and pungent odour and soft/hard consistency. All other attributes of PDO cheese were almost comparable with the results registered for the experimental cheeses of process 3 inoculated with the mesophilic strains, but the results showed by lactococci were most superimposable than those of leuconostocs, on average.

\subsection{Volatile organic compound composition}

Based on the above results, only the experimental cheeses inoculated with lactococci were compared with PDO cheese regarding the VOCs. The results from chromatographic analysis of the cheeses are reported in Table 5. In the headspace of the cheeses, 18 compounds were identified: 7 acids, 5 alcohols, 3 aldehydes and 3 esters. Control cheese CP3 was characterized by the lowest number of molecules registered, whereas only PDO cheese showed the presence of 18 compounds. The strain Lc. lactis subsp. cremoris PON153, which determined the highest number of volatile compounds among the experimental cheeses, generated a massive increase in the concentrations of all acids and shared a similar VOC profile with the PDO cheese. In particular, heptanoic acid, ethyl esanoate and ethyl octanoate were detected in PDO cheese and the cheese inoculated with Lc. lactis subsp. cremoris PON153. Ethyl decanoate, was detected also in cheese inoculated with Lc. lactis subsp. cremoris PON203 and with the triple Lc combination, but it was at a higher concentration in PDO cheese and the cheese processed with $L c$. lactis subsp. cremoris PON153. The last strain determined also the highest level of 2,3-butanediol, but, in general, high concentrations of alcohols were due to the Lc combination. The highest production of aldehydes was registered for the cheese inoculated with Lc. lactis subsp. cremoris PON203.

\subsection{Induction of the lytic cycle}

On the basis of the results obtained by the winter productions, lactococci were selected as starters for Vastedda-like cheese production. However, lysogenic strains cannot be proposed as starters during cheese making, since accidental and spontaneous induction of the lytic cycle leads to production failure (Franciosi et al., 2009). Thus, all three lactococci were subjected to a chemical induction of the lytic cycle. The results of PAm (not shown) excluded the presence of lysogenic bacteriophages in Lc. lactis subsp. cremoris PON36, PON153 and PON203.

\subsection{Summer production of Vastedda cheese}

On the basis of the results obtained by the winter productions, lactococci were selected for the four-season production of Vasteddalike cheese. For this reason, the Lactococcus strains needed to be tested during summer, when their dominance during processing can be compromised by the indigenous thermophilic LAB of raw milk which may find favourable conditions for development. All lactococci in single and multiple combinations, after growth in whey, were used to produce Vastedda-like cheese with raw milk during the last week of June and the first week of July at an industrial level to test the performance of the strains outside the experimental cheese factory. Room temperature was, on average $23.5^{\circ} \mathrm{C}$ during the night and $27.1{ }^{\circ} \mathrm{C}$ during the day. RAPD analysis (results not shown) allowed the recognition of each $L c$. lactis in the corresponding single inoculum, but only Lc. lactis subsp. cremoris PON153 was found at dominant levels after acidification, stretching of curd and 15 days of refrigerated storage of the cheese obtained with the mixed strain starter. Furthermore, VOC analysis of the resulting cheeses (Table 5 ) showed that also for the summer production the cheese processed with Lc. lactis subsp. cremoris PON153 showed the VOC profile most similar to that of the PDO cheese.

\section{Conclusions}

The uncontrolled evolution of microorganisms may lead to variable results in cheese production (Settanni and Moschetti, 2010). The selection of strains with given technological characteristics is important not only to drive the fermentation process, but also to maintain a certain typicality of traditional cheeses (Settanni et al., 2013). In order to set up a pool of LAB strains to be used for the four-season production of Vastedda-like cheese, the dynamics of twelve strains isolated from PDO cheeses and belonging to Lb. delbrueckii, Lc. lactis subsp. cremoris, Ln. mesenteroides subsp. mesenteroides and S. thermophilus, which displayed a dairy potential in vitro (Gaglio et al., 2014), were evaluated at pilot plant scale under controlled conditions in different single or multiple inocula. On the basis of the results shown for the winter and summer productions, at pilot scale and industrial level, respectively, and combining VOC and sensory evaluation, the multi-strain combination of lactococci was selected to act as starter preparation for the four-season production of Vastedda-like cheese. Even though the strains Lc. lactis subsp. cremoris PON36, PON153 and PON203 did not contain lysogenic phages, studies are being prepared to test their resistance to the most common dairy phages and to evaluate their performance in the several dairy factories producing PDO Vastedda della valle del Belìce cheese, which are gathered into a consortium for the protection of this traditional cheese production.

\section{Acknowledgments}

This work was financially supported by the project for industrial research and training PON01_02249 “Application of molecular biotechnologies and pro-technological microorganisms for the characterisation and valorisation of dairy and bakery chains of typical products" of the Italian Ministry of Education, University and Research (CUP: B11C11000430005). Mr. Simon Gill is also thanked for proofreading the final version in English.

\section{References}

Carlin, S., Versini, G., 2005. La caratterizzazione dei formaggi trentini attraverso la frazione volatile. In: Gasperi, F., Versini, G. (Eds.), Caratterizzazione di formaggi tipici dell'arco alpino: Il contributo della ricerca. Temi, San Michele all'Adige, Italy.

Cochran, P.K., Paul, J.H., 1998. Seasonal abundance of lysogenic bacteria in a subtropical estuary. Appl. Environ. Microbiol. 64, 2308-2312.

Donnelly, C.W., 2004. Growth and survival of microbial pathogens in cheese. In: Fox, P.F., McSweeney, P.L.H., Cogan, T.M., Guinee, T.P. (Eds.), Cheese: Chemistry, Physics and Microbiology. Chapman \& Hall, London, UK, pp. 541-560.

Franciosi, E., Settanni, L., Cavazza, A., Poznanski, E., 2009. Biodiversity and technological potential of wild lactic acid bacteria from raw cows' milk. Int. Dairy J. 19, 3-11.

Gaglio, R., Francesca, N., Di Gerlando, R., Cruciata, M., Guarcello, R., Portolano, B., Moschetti, G., Settanni, L., 2014. Identification, typing, and investigation of the dairy characteristics of lactic acid bacteria isolated from 'Vastedda della valle del Belìce' cheese. Dairy Sci. Technol. 94, 157-180.

Garde, S., Babin, M., Gaya, P., Nuñez, M., Medina, M., 1999. PCR amplification of the gene acmA differentiates Lactococcus lactis subsp. lactis and L. lactis subsp. cremoris. Appl. Environ. Microbiol. 65, 5151-5153.

ISO, 2003. ISO 13299. Sensory Analysis - Methodology - General Guidance for Establishing a Sensory Profile. International Standardisation Organisation, Geneva, Switzerland.

Kosikowski, F.V., 1958. Problems in the Italian soft cheese industy. J. Dairy Sci. 41, 455-458.

Leite, S.E., Montenegro, S.T.L., de Oliveira, L.E., 2006. Sensitivity of spoiling and pathogen food-related bacteria to Origanum vulgare L. (Lamiaceae) essential oil. Braz. J. Microbiol. 37, 527-532.

Micari, P., Sarullo, V., Sidari, R., Caridi, A., 2007. Physico-chemical and hygienic characteristics of the Calabrian raw milk cheese, Caprino d'Aspromonte. Turk. J. Vet. Anim. Sci. $31,55-60$. 
Mucchetti, G., Neviani, E., 2006. Microbiologia e tecnologia lattiero-casearia. Qualità e sicurezza. Tecniche Nuove, Milan, Italy.

Mucchetti, G., Bonvini, B., Remagni, M.C., Ghiglietti, R., Locci, F., Barzaghi, S., Francolino, S., Perrone, A., Rubiloni, A., Campo, P., Gatti, M., Carminati, D., 2008. Influence of cheesemaking technology on composition and microbiological characteristics of Vastedda cheese. Food Control 19, 119-125.

Niro, S., 2011. Innovazione di processo e di prodotto in formaggi a pasta filata. . PhD thesis Università degli Studi del Molise, Italy.

Panoff, J.M., Legrand, S., Thammavongs, B., Boutibonnes, P., 1994. The cold shock response in Lactococcus lactis subsp lactis. Curr. Microbiol. 29, 213-216.

Parente, E., Cogan, T.M., 2004. Starter Cultures: General Aspects. Elsevier, London, UK.

Parente, E., Moschetti, G., Coppola, S., 1998. Starter cultures for Mozzarella cheese. Ann. Microbiol. Enzimol. 48, 89-109.

Pérez, G., Cardell, E., Zárate, V., 2002. Ramdom amplified polymorphic DNA analysis for differentiation of Leuconostoc mesenteroides subspecies isolated from Tenerife cheese. Lett. Appl. Microbiol. 34, 82-85.

Salvadori del Prato, O., 1998. Trattato di Tecnologia Casearia. Edagricole, Bologna, Italy.
Settanni, L., Moschetti, G., 2010. Non-starter lactic acid bacteria used to improve cheese quality and provide health benefits. Food Microbiol. 27, 691-697.

Settanni, L., Franciosi, E., Cavazza, A., Cocconcelli, P.S., Poznanski, E., 2011. Extension of Tosèla cheese shelf-life using non-starter lactic acid bacteria. Food Microbiol. 28, 883-890.

Settanni, L., Di Grigoli, A., Tornambé, G., Bellina, V., Francesca, N., Moschetti, G., Bonanno, A., 2012a. Persistence of wild Streptococcus thermophilus strains on wooden vat and during the manufacture of a Caciocavallo type cheese. Int. J. Food Microbiol. 155, 73-81.

Settanni, L., Miceli, A., Francesca, N., Moschetti, G., 2012b. Investigation of the hygienic safety of aromatic plants cultivated in soil contaminated with Listeria monocytogenes. Food Control 26, 213-219.

Settanni, L., Gaglio, R., Guarcello, R., Francesca, N., Carpino, S., Sannino, C., Todaro, M., 2013. Selected lactic acid bacteria as a hurdle to the microbial spoilage of cheese: application on a traditional raw ewes' milk cheese. Int. Dairy J. 32, 126-132.

Todaro, M., Francesca, N., Reale, S., Moschetti, G., Vitale, F., Settanni, L., 2011. Effect of different salting technologies on the chemical and microbiological characteristics of PDO Pecorino Siciliano cheese. Eur. Food Res. Technol. 233, 931-940. 